OPEN ACCESS

Edited by:

Soonja Choi

San Diego State University,

United States

Reviewed by:

Birgit Hellwig,

University of Cologne, Germany

Shanley Allen,

University of Kaiserslautern, Germany

*Correspondence:

Alan Rumsey

alan.rumsey@anu.edu.au

Specialty section: This article was submitted to

Language Sciences,

a section of the journal

Frontiers in Communication

Received: 15 July 2019 Accepted: 11 March 2020

Published: 15 April 2020

Citation:

Rumsey A, Reed LW and Merlan F (2020) Ku Waru Clause Chaining and

the Acquisition of Complex Syntax.

Front. Commun. 5:19

doi: 10.3389/fcomm.2020.00019

\section{Ku Waru Clause Chaining and the Acquisition of Complex Syntax}

\author{
Alan Rumsey ${ }^{1 *}$, Lauren W. Reed ${ }^{1}$ and Francesca Merlan ${ }^{2}$ \\ 'School of Culture, History and Language, College of Asia and the Pacific, Australian National University, Acton, ACT, \\ Australia, ${ }^{2}$ School of Archaelogy and Anthropology, College of Arts and Social Sciences, Australian National University, \\ Acton, ACT, Australia
}

How do children learn to understand and use complex syntactic constructions? In English, Diessel (2004) shows that they do so in two different ways. Complex sentences with dependent clauses (e.g., "Peter promised that he would come") develop out of simple sentences that are gradually expanded into multi-clause ones. Complex sentences with coordinate clauses (e.g., "He tried hard, but he failed") develop by integrating two independent sentences into a single two-clause unit. Here we expand on that research by focusing on the acquisition of a kind of complex syntactic structure which involves both dependency and coordination-the clause chain-in Ku Waru, a Papuan language spoken in the Western Highlands of Papua New Guinea. Clause chains are constructions coordinating multiple clauses in sequence, where the non-final or "medial" clauses are in a dependent relationship with the final clause. One function of clause chains, which is often taken to be the prototypical one, is to refer to a series of events in sequence. Some Ku Waru clause chains do refer to sequential events. Other Ku Waru clause chains containing particular verbs refer to single events, sometimes with the particular verb providing aspectual or adverbial qualification ("keep doing," "do quickly," etc.). In this article, we track the acquisition of several different kinds of clause chains based on longitudinal recordings of four children acquiring Ku Waru as their first language between the ages of $1 \frac{1 / 2}{2}$ and 5 . We show that, although there are differences among the children in the ages at which they acquire the various kinds of clause chain, all four of them follow the same series of steps in doing so. In conclusion, we compare our findings to Diessel's for English. We find that they are similar in some ways and different in others, which may be related to the differences between subordinate constructions, coordinate non-dependent constructions and coordinate-dependent constructions.

Keywords: child language acquisition, Papuan languages, clause chaining, switch-reference, event structure, Ku Waru, complex syntax

\section{INTRODUCTION}

This article focuses on children's acquisition of clause chaining in the Papuan language Ku Waru. We define a clause as a linguistic unit which: (a) expresses a proposition, and (b) consists of an explicit or implied subject and a predicate. Clause chains in languages like Ku Waru are constructions which contain: (a) one or more non-final clauses containing verbs that are either partially specified or otherwise marked as non-final; and (b) a final clause containing a verb that is fully specified (Haspelmath, 1995, p. 21; Longacre, 2007, p. 374-376; Sarvasy, 2015, p. 665-666). 
For $\mathrm{Ku}$ Waru in particular it must be added that some of the non-final verbs in clause chains are fully specified for person and number, but not for their tense, which is determined by that of the final verb. As in other clause chaining languages such as the ones discussed by Foley and Olson (1985) and Van Valin and LaPolla (1997), non-final clauses in Ku Waru are linked to their final clause in a relationship that shows elements of dependency and coordination. Non-final clauses are dependent, because they depend on the final verb in the chain for their full inflectional specification (Roberts, 1988, p. 49-50). At the same time, nonfinal clauses show elements of coordination, because they behave somewhat independently. For example, in some clause chaining languages, question particles may have scope over only some of the clauses in a chain, which suggests that the clauses are in a coordinate, not subordinate relationship to one another (Foley, 2010, p. 30). From a Eurocentric perspective, this seems paradoxical because the dependency relation is usually thought to be associated with subordination rather than coordination. As Sarvasy (2015, p. 666) points out, this in-between status of clause chains presents a puzzle for formal theories of syntax.

The prototypical function of clause chains is often reported to be the narration of discrete, sequential events. For example, Thurman (1975) states that " $t$ ] he emphasis of chaining. .. is on the conjoining of a number of clauses in chronological sequence" (p. 342). The length of chains is often emphasized. Weisser (2015, p. 4) begins his definition of clause chains by referring to them as "long sequences of a potentially infinite number of clauses within the same sentence" (italics our own). Dooley (2010, p. 13) does not consider languages "chaining" unless they have "long chains" that are "common in narrative" (p. 13). Sarvasy (2015, p. 666) cites metaphors regarding clause chains that emphasize both length and sequentiality, such as "an engine... [pulling] along a string of cars" (Longacre, 2007, p. 399) and "beads on a necklace" (Foley, 1986, p. 77). As we will show, the emphasis in some of the literature on length and event sequentiality in clause chaining does not hold as strongly for Ku Waru.

In this article, we have two aims. One is to provide a detailed account of how $\mathrm{Ku}$ Waru children learn to understand and produce clause chains. Clause chaining and similar multi-clause constructions are fairly common among the languages of the world, but not among commonly-studied languages. Clause chains have not yet been the object of any detailed acquisition studies (although cf. Sarvasy, 2019; and this collection). Our second aim is to develop some implications of those findings for the general understanding of the acquisition of complex syntaxan area of inquiry that has so far been based mainly on studies of English and a few other European languages. Before introducing the $\mathrm{Ku}$ Waru case in the next section, we will first provide a brief summary of an English-based study that provides our basis for comparison.

\section{The Acquisition of Complex Sentences in English}

The most detailed and influential study of the acquisition of complex sentences in any language is the English-based study by Diessel (2004). Diessel (2004, p. 1, 42-43) outlines a basic distinction between complex sentences involving coordinate clauses (e.g., "He tried hard, but he failed") and complex sentences with a main or "matrix" clause and a subordinate clause (e.g., "Peter promised that he would come"). In the former example, the two clauses are independent and linked by "but"; whereas in the latter, the clause "that he would come" is subordinate to the matrix clause, "Peter promised." Diessel defines prototypical subordinate clauses as being "marked as dependent structures that are formally incomplete without the matrix clause" (p. 48). Diessel's study of thousands of instances of subordinate clauses from five children between the ages of $1 ; 8^{1}$ and $5 ; 1$ reveals a consistent pattern to the ways in which complex sentences with subordinate clauses are acquired. Namely, the children's early productions of them are based on "lexically specific," common exemplars of constructions containing subordinate clauses (p. 4-5). The children then use these sentences as a basis from which to produce and understand more innovative sentences (p. 142).

The first multi-clause structures that children produce that seem to consist of a matrix + subordinate clause actually "contain a single proposition (i.e., they describe a single situation)" (Diessel, 2004, p. 3). An example from the speech of a child at age $1 ; 11$ is "I wanna see it." Another example at 2:2 is "I think it's a little bear" (p. 3). Although the verbs "wanna" and "think" in these examples function grammatically like matrix verbs, both utterances designate only one state of affairs, not two (p. 175176). The apparent matrix verbs in children's early productions of multi-clause structures function as modals, temporal markers, epistemic markers, attention getters, and markers which guide the hearer's interpretation of the associated complement clause (p. 175-176). Children then go on to use the "frame" they have acquired from these lexically specific exemplars (such as "I wanna...") and use them to construct multi-clause utterances which can represent two independent states of affairs (such as "Peter promised that he would come").

English-speaking children's learning of coordinate constructions follows a different path. Coordinate sentence constructions are ones in which two or more clauses, each of which in its full form could potentially stand on its own, are combined to form a single sentence that expresses some kind of logical or pragmatic connection between the clauses, e.g., "There's the lion and here's the kitty," "Don't touch the camera because it's broken." Diessel (2004, p. 158-169) shows that in English-speaking children's first productions of such sentences, the clauses are generally spoken as intonationally distinct units, often within separate conversational turns, e.g., Child: "Don't touch the camera"/Adult: "Why"/Child: "Because it's broken" (Diessel, 2004, p. 4). In short, as Diessel puts it, while subordinate clauses "evolve via clause expansion," coordinate clauses develop though a process of "clause integration" (Diessel, 2004, p. 4, italics in original).

Diessel's findings regarding the acquisition of complex sentences have been supported by other acquisition studies

\footnotetext{
${ }^{1}$ Here and below, when giving the ages of children we follow the format which is standard in child language studies, where years and months are separated by a semicolon, e.g., "1;8" means one year and eight months.
} 
focused on English (Diessel and Tomasello, 2005; Kidd et al., 2006, 2007; Brandt et al., 2009; Köymen et al., 2016) and German (Kidd et al., 2007; Brandt et al., 2008, 2009). Given that all these studies focussed exclusively on subordinate-dependent and coordinate-independent constructions, a question that arises is: how similar or different would the findings be if we focus on coordinate-dependent ones? In this paper, we investigate this question with regard to the acquisition of multi-clause, coordinate-dependent constructions in Ku Waru: namely, clause chains. Before doing so, we will first introduce the speakers of $\mathrm{Ku}$ Waru, relevant aspects of its grammar, and the methodology of the study.

\section{THE KU WARU LANGUAGE AND ITS SOCIAL SETTING}

$\mathrm{Ku}$ Waru is spoken by $\sim 10,000$ people living in the rural Papua New Guinea Highlands. The language is still being robustly acquired as a first language by children. It belongs to the Trans New Guinea family of Papuan languages ${ }^{2}$, and, more immediately, to a dialect continuum within the Chimbu-Wahgi branch of that family. This branch includes what Ethnologue ${ }^{3}$ classifies as four distinct languages: Melpa, Mbo-Ung, Imbonggu and Umbu-Ungu (Eberhard et al., 2019). Ku Waru is a dialect of Mbo-Ung (ISO code mux). Tok Pisin, a largely Englishbased creole and one of Papua New Guinea's national languages, is spoken by most $\mathrm{Ku}$ Waru speakers aged 50 and younger. Children are exposed to Tok Pisin both at home and when they enter primary school.

For Ku Waru speakers who are living in their rural homeland, the local economy is largely a subsistence one, based on intensive cultivation of sweet potatoes, taro, and a wide range of other crops; raising of pigs; and use of locally grown materials for building houses and agricultural infrastructure. There is now also intensive engagement with the cash economy, based largely on growing of coffee for the world market and vegetables for sale to town dwellers.

\section{RELEVANT ASPECTS OF KU WARU GRAMMAR}

\section{Introduction to Ku Waru Morphosyntax and Clause Chaining}

Like many other Trans New Guinea languages, Ku Waru is rigorously verb-final: if there is a verb in the clause ${ }^{4}$, it always

\footnotetext{
${ }^{2}$ The designation "Papuan" refers not to a language family, but rather, in a residual way, to languages of New Guinea and the nearby islands which do not belong to the Austronesian language family. Within that residual group there are a number of more-or-less well-established language families, the largest of which is the Trans New Guinea one. For further details see Pawley and Hammerström (2017) and Rumsey (2019).

${ }^{3}$ Ethnologue is a widely-cited online source that provides statistics and other information on the languages of the world, at https://www.ethnologue.com/ (Eberhard et al., 2019, accessed 15 November, 2019).

${ }^{4}$ As in many languages, equational, or identifying clauses with meanings like "This is my house" are verbless in Ku Waru, with the equational meaning expressed by juxtaposition: "This my house," etc.
}

comes last. In clauses with both a subject (agent) and an object, the word order is usually agent-object-verb, but sometimes (about $10 \%$ of the time) it is object-agent-verb. Verb inflections fall into three distributional classes, depending on their possible position within clause chains: Final, Non-Final and what we call the "Chameleon" class, for reasons which will become clear below (see Table 1). Inflections in the Final class only occur in final clauses (with a partial exception that we will outline in section The Optative-Final Construction as a Clause Chain?). Inflections in the Non-Final class only occur in non-final clauses. Inflections in the Chameleon class may occur in either final or non-final clauses, with associated differences in meaning. Note that here, we break with the Papuanist tradition where all verbal inflections that occur in non-final position are referred to as "medial" (Sarvasy, 2015, p. 665). Instead, we use the term Medial in reference to a specific Ku Waru verbal inflection, which is the sole member of the Non-Final class. Hereafter, where we capitalize Final or Non-Final, we are referring to the Ku Waru verb class; where we leave final and non-final in lower case, we are referring to the clause position in the sentence. Medial will be capitalized throughout, as it refers to a specific Non-Final inflection in Ku Waru.

The class of Final verbs have suffixes that show the person and number of the subject, and suffixes that mark tense, aspect and mood (see Table 1). Many of the suffixes are portmanteau ones, expressing two or more categories in a single form (for example, the suffix - $b u$ indexes first-person, singular subject, and future tense). Many verbal meanings are expressed by the combination of an inflected verb and a non-inflecting "preverb" that carries most of the lexical meaning. Examples of this construction may be found in (2), (38), and (48). Case relations are expressed by markers that attach to the last word of the noun phrase. These include the ergative marker $-n i$ as in (8), the genitive marker - nga as in (1), and the comitative marker -kin as in $(9)^{5}$.

Trans New Guinea languages like Ku Waru and Nungon (Sarvasy, this collection) are characterized by clause chaining (see section Introduction), verb-final word order, and switchreference (Pawley and Hammerström, 2017). Example (1) presents an adult $\mathrm{Ku}$ Waru clause chain.

(1) $a b-a y l$ woman-DEF ${ }^{6}$ go-MED.3SG $3 S G-G E N$ place molu-rum. stay/be-RP:3SG

"The woman went home to her place and she stayed there."

or, more literally, "The woman, having gone, stayed at her place."

This sentence contains two clauses, "the women went" and "[she] stayed." The verb in the first clause, pupa, takes a Medial suffix.

\footnotetext{
${ }^{5}$ For further details about the grammar of Ku Waru see Merlan and Rumsey (1991, p. 322-343).

${ }^{6}$ The interlinear glossing in this article follows the Leipzig glossing rules, for which see https://www.eva.mpg.de/lingua/resources/glossing-rules.php. The abbreviations we use that are not listed there are HAB, habitual; IMM, imminent; JUS, jussive; MED, medial; OPT, optative; PPR, present progressive; RP, remote past; SR1, switch reference 1; SR2, switch reference 2.
} 
TABLE 1 | Some representative Ku Waru verb paradigms.

\begin{tabular}{|c|c|c|c|c|c|c|c|c|c|c|}
\hline \multicolumn{2}{|c|}{ Class } & \multicolumn{5}{|c|}{ Final } & \multirow{2}{*}{$\frac{\text { Non-final }}{\text { Medial }}$} & \multicolumn{3}{|c|}{ Chameleon } \\
\hline Root & Subject & $\begin{array}{l}\text { Imperative- } \\
\text { Hortative }\end{array}$ & $\begin{array}{l}\text { Present } \\
\text { Progressive }\end{array}$ & Perfective & $\begin{array}{l}\text { Remote } \\
\text { Past }\end{array}$ & Habitual & & $\begin{array}{l}\text { Future/ } \\
\text { Imminent }\end{array}$ & $\begin{array}{l}\text { Subjunctive/ } \\
\text { Switch- } \\
\text { reference 1 }\end{array}$ & $\begin{array}{l}\text { Optative/ } \\
\text { Switch- } \\
\text { reference } 2\end{array}$ \\
\hline $\begin{array}{l}\text { pu- "go" } \\
\text { nyi- "say" } \\
\text { to- "hit" }\end{array}$ & $1 \mathrm{sg}$ & - & $\begin{array}{l}\text { pukur } \\
\text { nyikir } \\
\text { tokur }\end{array}$ & $\begin{array}{l}\text { pud } \\
\text { nyid } \\
\text { tud }\end{array}$ & $\begin{array}{l}\text { purud } \\
\text { nyirid } \\
\text { turud }\end{array}$ & $\begin{array}{l}\text { pulyo } \\
\text { nyilyo } \\
\text { tolyo }\end{array}$ & $\begin{array}{l}\text { pup } \\
\text { nyib } \\
\text { top }\end{array}$ & $\begin{array}{l}\text { pubu } \\
\text { nyibu } \\
\text { tobu }\end{array}$ & $\begin{array}{l}\text { pulka } \\
\text { nyilka } \\
\text { tolka }\end{array}$ & $\begin{array}{l}\text { pab } \\
\text { nyab } \\
\text { tab }\end{array}$ \\
\hline $\begin{array}{l}\text { pu- "go" } \\
\text { nyi- "say" } \\
\text { to- "hit" }\end{array}$ & $2 \mathrm{sg}$ & $\begin{array}{l}\text { pa } \\
\text { nya } \\
\text { to }\end{array}$ & $\begin{array}{l}\text { pukun } \\
\text { nyikin } \\
\text { tokun }\end{array}$ & $\begin{array}{l}\text { pun } \\
\text { nyin } \\
\text { tun }\end{array}$ & $\begin{array}{l}\text { purun } \\
\text { nyirin } \\
\text { turun }\end{array}$ & $\begin{array}{l}\text { pulto } \\
\text { nyilto } \\
\text { tolto }\end{array}$ & $\begin{array}{l}\text { puk } \\
\text { nyik } \\
\text { tok }\end{array}$ & $\begin{array}{l}\text { nyini } \\
\text { puni } \\
\text { toni }\end{array}$ & $\begin{array}{l}\text { pulkuna } \\
\text { nyilkuna } \\
\text { tolkuna }\end{array}$ & $\begin{array}{l}\text { pan } \\
\text { nyan } \\
\text { tan }\end{array}$ \\
\hline $\begin{array}{l}\text { pu- "go" } \\
\text { nyi- "say" } \\
\text { to- "hit" }\end{array}$ & $3 s g$ & - & $\begin{array}{l}\text { pukum } \\
\text { nyikim } \\
\text { tokum }\end{array}$ & $\begin{array}{l}\text { pum } \\
\text { nyim } \\
\text { tum }\end{array}$ & $\begin{array}{l}\text { purum } \\
\text { nyirim } \\
\text { turum }\end{array}$ & $\begin{array}{l}\text { pulym } \\
\text { nyilym } \\
\text { tolym }\end{array}$ & $\begin{array}{l}\text { púpa } \\
\text { nyíba } \\
\text { tópa }\end{array}$ & $\begin{array}{l}\text { puba } \\
\text { nyiba } \\
\text { toba }\end{array}$ & $\begin{array}{l}\text { pulka } \\
\text { nyilka } \\
\text { tolka }\end{array}$ & $\begin{array}{l}\text { púpiyl } \\
\text { nyípiyl } \\
\text { túpiyl }\end{array}$ \\
\hline $\begin{array}{l}\text { pu- "go" } \\
\text { nyi- "say" } \\
\text { to- "hit" }\end{array}$ & $1 d u$ & $\begin{array}{l}\text { pábul } \\
\text { nyábul } \\
\text { tábul }\end{array}$ & $\begin{array}{l}\text { pukubul } \\
\text { nyikibul } \\
\text { tokubul }\end{array}$ & $\begin{array}{l}\text { pubul } \\
\text { nyibul } \\
\text { tubul }\end{array}$ & $\begin{array}{l}\text { purubul } \\
\text { nyiribul } \\
\text { turubul }\end{array}$ & $\begin{array}{l}\text { pulybulu } \\
\text { nyilybulu } \\
\text { tolybulu }\end{array}$ & $\begin{array}{l}\text { pup } \\
\text { nyib } \\
\text { nyib }\end{array}$ & $\begin{array}{l}\text { pubulu } \\
\text { nyibulu } \\
\text { tobulu }\end{array}$ & $\begin{array}{l}\text { pulkubula } \\
\text { nyilkubula } \\
\text { tolkubula }\end{array}$ & $\begin{array}{l}\text { pábiyl } \\
\text { nyábiyl } \\
\text { pábiyl }\end{array}$ \\
\hline $\begin{array}{l}\text { pu- "go" } \\
\text { nyi- "say" } \\
\text { to- "hit" }\end{array}$ & $2 / 3 d u$ & $\begin{array}{l}\text { payl } \\
\text { nyayl } \\
\text { tayl }\end{array}$ & $\begin{array}{l}\text { pukubil } \\
\text { nyikibil } \\
\text { tokubil }\end{array}$ & $\begin{array}{l}\text { pungl } \\
\text { nyingl } \\
\text { tungl }\end{array}$ & $\begin{array}{l}\text { puringl } \\
\text { nyiringl } \\
\text { turingl }\end{array}$ & $\begin{array}{l}\text { pulybeli } \\
\text { nyilybeli } \\
\text { tolybeli }\end{array}$ & $\begin{array}{l}\text { pul } \\
\text { nyil } \\
\text { tol }\end{array}$ & $\begin{array}{l}\text { pungli } \\
\text { nyingli } \\
\text { tongli }\end{array}$ & $\begin{array}{l}\text { pulkubela } \\
\text { nyilkubela } \\
\text { tolkubela }\end{array}$ & $\begin{array}{l}\text { pangl } \\
\text { nyangl } \\
\text { tangl }\end{array}$ \\
\hline $\begin{array}{l}\text { pu- "go" } \\
\text { nyi- "say" } \\
\text { to- "hit" }\end{array}$ & $1 \mathrm{pl}$ & $\begin{array}{l}\text { pámul } \\
\text { nyámul } \\
\text { támul }\end{array}$ & $\begin{array}{l}\text { pukumul } \\
\text { nyikimul } \\
\text { tokumul }\end{array}$ & $\begin{array}{l}\text { pumul } \\
\text { nyimul } \\
\text { tumul }\end{array}$ & $\begin{array}{l}\text { purumul } \\
\text { nyirimul } \\
\text { turumul }\end{array}$ & $\begin{array}{l}\text { pulymulu } \\
\text { nyilymulu } \\
\text { tolymulu }\end{array}$ & $\begin{array}{l}\text { pup } \\
\text { nyib } \\
\text { top }\end{array}$ & $\begin{array}{l}\text { pumulu } \\
\text { nyimulu } \\
\text { tomulu }\end{array}$ & $\begin{array}{l}\text { pulkumula } \\
\text { nyilkumula } \\
\text { tolkumula }\end{array}$ & $\begin{array}{l}\text { pámiyl } \\
\text { nyámiyl } \\
\text { pámiyl }\end{array}$ \\
\hline $\begin{array}{l}\text { pu- "go" } \\
\text { nyi- "say" } \\
\text { to- "hit" }\end{array}$ & 2/3pl & $\begin{array}{l}\text { pai } \\
\text { nyai } \\
\text { tai }\end{array}$ & $\begin{array}{l}\text { pukumil } \\
\text { nyikimil } \\
\text { tokumil }\end{array}$ & $\begin{array}{l}\text { pung } \\
\text { nying } \\
\text { tung }\end{array}$ & $\begin{array}{l}\text { purung } \\
\text { nyiring } \\
\text { turung }\end{array}$ & $\begin{array}{l}\text { pulymeli } \\
\text { nyilymeli } \\
\text { tolymeli }\end{array}$ & $\begin{array}{l}\text { puk } \\
\text { nyik } \\
\text { tok }\end{array}$ & $\begin{array}{l}\text { pungi } \\
\text { nyingi } \\
\text { tongi }\end{array}$ & $\begin{array}{l}\text { pulkumela } \\
\text { nyilkumela } \\
\text { tolkumela }\end{array}$ & $\begin{array}{l}\text { pang } \\
\text { nyang } \\
\text { tang }\end{array}$ \\
\hline
\end{tabular}

Like all $\mathrm{Ku}$ Waru Medial verbs, it has the same subject as the final verb, in this case the woman. The Medial verb is specified for person and number but not for tense, aspect or mood (TAM). For those it is dependent on the verb in the final clause, which is inflected for Remote Past in addition to third person singular person/number. This construction satisfies our definition of a clause chain in section Introduction, in that the verb in the non-final clause is partially specified and the verb in the final clause is fully specified. The verb in the non-final clause is dependent on the verb in the final clause for its full TAM specification.

As suggested by our use of "and" in the free translation of (1), the semantic relation between the two clauses is similar to that in an English coordinate construction. The main semantic difference between $\mathrm{Ku}$ Waru and English in this respect is in the understood temporal relation between the two coordinands. In English clause sequences, the use of "and" between two clauses does not by itself specify any particular temporal relation between them. However, in $\mathrm{Ku}$ Waru clause sequences which refer to two distinct events, if the first clause has a Medial verb and following clause has a Final verb, the event referred to in the first clause is categorically understood to have taken place before the one referred to in the following clause.

The following example presents a longer $\mathrm{Ku}$ Waru clause chain, and one that is typical of narrative contexts:
(2) olyo

we (1PL)

kalyip

peanut

$n o-b$

eat-MED.1

pu-mulayl

go-FUT.1PL:DEF

"We'll go down to the markets and buy peanuts and eat them, and get some flour balls and eat them and then we'll go."

Note that in terms of coordination, as in (1) each event in (2) is understood to have occurred in the same sequential order as the clauses that refer to them. Returning to dependency, note that the $-p$ suffix on the Medial verbs in (2) is underspecified for number; it may refer to a first-person, singular subject ("I"); a first-person, dual subject ("the two of us"); or a first-person, plural subject ("we") (see Table 1). In (2), the Medial verbs are dependent on the Final verb for not only their TAM marking, but their full person-number marking too. In (2), the pronoun olyo does clarify this at the beginning of the sentence, but subjects are not always overtly specified in $\mathrm{Ku}$ Waru. In keeping with this example and others below, and with other treatments of clause chains such as those in Foley and Olson (1985) and Van Valin and LaPolla (1997), we characterize clause chains in Ku Waru as both coordinate and dependent. 
The paradigms shown in Table $\mathbf{1}$ include all the forms for three of the most common Ku Waru verbs. The verbs shown there are representative in that they show how the forms of the suffixes differ depending on the last vowel in the $\operatorname{root}^{7}$.

In addition to the verb forms shown on Table 1, there is a single Jussive form that is used for infinitive-like complements of verbs of speaking (3) and for "polite" commands.

$$
\begin{aligned}
& \text { (3) } p u-i \quad \text { nyi-rim } \\
& \text { go-JUS say-RP:3SG } \\
& \text { "He said to go." }
\end{aligned}
$$

The Jussive is marked by a suffix $-i$ that is added to the verb root (with small associated changes to the form of some roots) ${ }^{8}$.

\section{The Chameleon Class}

We now turn to the third verb class, the Chameleon class. We show how the three inflections of this class differ systematically in meaning depending on their syntactic environment. When occurring in final position, the Subjunctive/Switch-Reference 1 inflection has a modal meaning "should," "would, "could," etc., as exemplified in (4).

$$
\begin{array}{lll}
\text { (4) } \text { el-ayl } & \text { nanu } & \text { te-lka } \\
\text { fight-DEF } & \text { I.myself } & \text { do-SBJV/SR1:1/3S } \\
\text { "I myself should fight." } &
\end{array}
$$

When used in non-final position, Subjunctive/Switch-Reference 1 inflection has a switch-reference meaning. In this position, the form indicates a switch of subject between the verb that is marked that way and the following one. Example (5) illustrates this.
(5) tripela
three

$\begin{array}{lll}\text { nyi-lkuna } & \text { na-n } & \text { tupela } \\ \text { say-SBJV/SR1:2SG } & \text { I-ERG } & \text { two }\end{array}$
nyi-kir
say-PPR:1SG
"You have said three and I say two."

Like the temporal relation between a Medial and Final verb in (1), the event that is expressed by a Switch-Reference 1 (hereafter "SR1") verb precedes the one that is predicated by the Final verb. Given the different meanings of Subjunctive and SR1, we consider these to be two distinct grammatical categories within $\mathrm{Ku}$ Waru. Throughout the rest of this article, we accordingly gloss them as SBJV or SR1, depending on whether the verb occurs in final or non-final position.

There is a parallel difference in function between Optative and Switch-Reference 2 (hereafter "SR2"). In final position, the Optative/SR2 form expresses optative modality, expressing a wish or desire. An example is (6).
(6) na ola mol-ab
I up be/stand-OPT/SR2:1SG
"I want to stand up."

In non-final position, the SR2 forms mark a switch of subject, but with a different temporal relationship than for SR1 verbs (as in 5) and Medial verbs (as in 1). The event or state of affairs expressed

\footnotetext{
${ }^{7}$ For roots in which the last vowel is $a$ or $e$, the suffixes take the same for as the roots $p u$ - and nyi-, respectively.

${ }^{8}$ For details see Merlan and Rumsey (1991, p. 343, 334).
}

by an SR2 verb encompasses the one that is predicated by the following verb. An example is (7).

$\begin{array}{lll}\text { (7) na naa mol-ab } & \text { tiring } \\ \text { I not be/stay-OPT/SR2.1SG do:RP:2/3PL } \\ \text { "When I wasn't there, they did it [fought]." }\end{array}$

Switch-reference is widespread in Papuan languages (Foley, 1986). However, unlike in other Papuan languages, the use of switch-reference in $\mathrm{Ku} \mathrm{Waru}$ is extremely rare (see sections Adults' and Older Children's Speech to the Target Children in $\mathrm{Ku}$ Waru and The Emergence of Clause Chaining on adult and child switch-reference production, respectively). A far more common way of expressing the meanings of (5) and (7) would be to either break them into two sentences, as in (8), or to rephrase with a subordinate clause marked with the comitative ("with") marker, as in (9).
(8) tripela nyikin. na-n tupela nyi-kir three say-PPR:2SG I-ERG two say-PPR:1SG "You say three. I say two."
(9) na naa molu-rud-kin ${ }^{9}$ tiring
I not be/stay-RP:1SG-COM do:RP:2/3PL
"When I wasn't there, they did it."

The third verbal inflection in the Chamleon class is the Future/Imminent. In final position it indicates future tense and/or intention on the part of the subject.
(10) napilya nekid yunu pu-ba Nebilyer other.side he.himself go-FUT/IMM.3SG "He himself will cross/wants to cross the Nebilyer River."

In non-final position, the Future/Imminent inflection specifies that the action/process/event referred to by the Future/Imminent verb is imminent in view of that referred to by the verb that follows. The two verbs have the same subject. If it is a sentient one, the usual sense is that he or she performed the action referred to by the second verb with the intention of thereby (or thereafter) performing the first. An example is (11).

(11) nu nabolka ul tini u-n you what thing do:2SG:FUT/IMM come-PRF:2SG "What have you come here to do?"

As can be seen, while the difference in meaning between Subjunctive and SR1 and between Optative and SR2 is stark, there is an obvious connection between the meanings of Future and Imminent. Nevertheless, we treat Future and Imminent as distinct verb categories. This is because the Future is a true tense-mood category, directly expressing the tense and/or mood of a verb in relation to the time of speaking, and/or avowed intention of the speaker; whereas the Imminent can be analyzed as indicating the time of an event in relation to the event that is referred to in the following clause, and/or its purposive relation to that event.

\footnotetext{
${ }^{9}$ Note that the comitative suffix -kin here marks this verb along with the two preceding words as a subordinate temporal clause, in this case with the same temporal relation of encompassment as is realized with the SR2 form in (7).
} 
In section Introduction, we stated that clause chains are constructions which contain two components: (a) a series of nonfinal clauses containing verbs that are either partially specified or otherwise marked as non-final; and (b) a final clause containing a verb that is fully specified. When occurring in non-final position, SR1, SR2, and Imminent verbs are fully specified for person and number, but not for their tense, which is determined by that of the final verb. Moreover, they are linked to the final clause in another way, namely, they mark a switch of subject and/or a particular causal and temporal relation between their host clause and that of the final clause. Hence, by our definition, constructions containing these verbs in non-final position are clause chains.

\section{Clause Chains vs. Serial Verb Constructions in Ku Waru}

The most common category of verb found as predicate of nonfinal clauses in $\mathrm{Ku}$ Waru clause chains is Medial. While the Medial verbs in (1) and (2) clearly refer to distinct events in sequence, this is not always true of Medial verbs. Some combinations of particular verbs have idiomatic meanings in which they predicate a single event. For example, the combination of the verb nyi- "say" with Medial marking followed by the verb pilyi- "hear" means "think" or "believe." The combination of kud- "pull" with Medial marking followed by nyi"say" means "tell." It could be argued that these combinations are more serial verb-like than clause chain-like, because they predicate single events (Aikhenvald, 2018). But consider such cases in $\mathrm{Ku}$ Waru as the frequently occurring combination lyi- "get" with Medial marking, followed by me- "carry" with Medial marking, followed by $p u$ - "go," which gives the meaning "take." It is unclear whether we should treat "get," "carry," and "go" in this combination as single events or as component sub-events in sequence. Indeed, in previous publications (e.g., Merlan and Rumsey, 1991, 2017; Rumsey, 2017), we have used the term "serial verb construction" in reference to what for present purposes are being treated as "clause chains." However, because these lexicalised combinations are structured like clause chains, and because of the difficulty in determining if some (like "take") constitute single or multiple events, here we treat them all as clause chains, privileging form over semantics for current purposes.

Besides the lexically specific uses of particular verb combinations, there are other combinations in which a particular verb combines with an open-ended range of others to convey a grammaticalized aspectual meaning. The verb that is most commonly used that way is mol- ("stay," "be"), which combines with a preceding Medial verb to convey the durative aspectual meaning "do at length." An example is (12).

(12) $n u \quad$ kana- $k \quad$ molu-run?
you see-MED.2 be/stay-RP:2SG
"Were you watching?"

In (12), the seeing is durative. Compare this to (13) which does not have a following mol- ("stay," "be"), and hence where the seeing could have been instantaneous or fleeting rather than durative.

(13) nu kana-run
you see-RP:2SG
"Did you see?"

In other cases, the Medial verb conveys a meaning of the kind that in English would be expressed by an adverb. Examples are alte- "do again," laka- "do vigorously or forcefully" and lkisi- "do quickly." An example is (14).
(14) alte-pa
tim
again-MED.3SG
"He did it again."
do:PRF.3SG

Most of such adverb-like modifying verbs occur only as Medial verbs, not as Final ones. Where they do appear as Final verbs, these verbs have a different but clearly related meaning. For example, when lkisi- appears in Medial form, it means "do quickly," and when it appears in Final form, it means "run."

What the adverbial uses of these verbs and the aspectual ones in final position (such as mol-) have in common with each other, and with the lexicalized clause chains, is that all such cases involve sequences of two or more verbs that refer to a single event. We will show that this is particularly pertinent, given the stage at which $\mathrm{Ku}$ Waru children acquire these in comparison to the stage at which English-speaking children acquire single-event, multi-clause constructions (Diessel, 2004).

\section{Presence vs. Absence of Medial Verb Marking}

Uniquely among all $\mathrm{Ku}$ Waru verb inflections, suffixes of Medial verbs are sometimes omitted, leaving the root only, without any apparent difference in meaning. This happens occasionally in adult speech (see section Presence or Absence of Medial Marking in the Adults' Speech on adult Medial verbs), and more commonly in children's speech (section The Presence vs. Absence of Medial Verb Marking on children's Medial verb productions). Even without their suffixes, such verbs are still identifiable as Medial because they are in non-final position and because Medial verbs are the only ones that can occur in unsuffixed form. For that reason, we treat the absence of a suffix as morphologically distinctive in that environment, positively marking it with the null sign $-\varnothing$, which is glossed as MED:

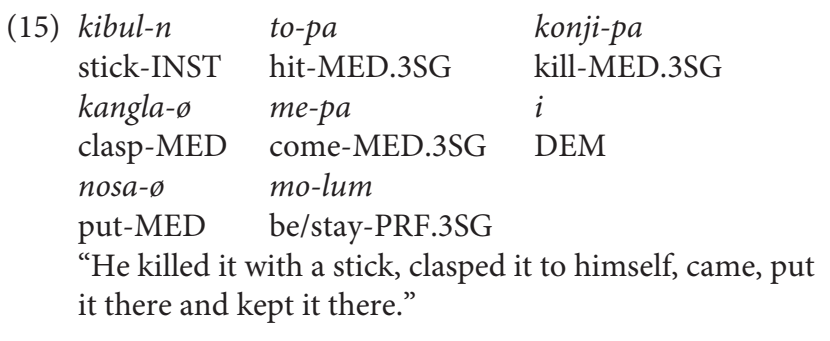

\section{The Optative-Final Construction as a Clause Chain?}

In addition to their use described in section The Chameleon Class, Optative verbs can be used in a particular kind of 
two-clause construction identifiable on the basis of intonation, grammatical features, and the semantic relation between the two clauses. The intonational pattern involves separate, highfalling pitch contours for each clause, with a larger fall and lower terminus for the second one. Grammatically, the first clause in this construction must have an Optative verb with a firstperson dual or plural subject, and the second clause must have an Imperative or Jussive verb, or an Optative one with a firstperson dual or plural subject. We term this an Optative-Final construction. The semantic and temporal relation between the two clauses is that the action enjoined by the second clause is meant to be preparatory to the action enjoined by the first. Examples are (16) and (17).

$$
\begin{array}{ll}
(16)(=21) & \begin{array}{l}
\text { pabiyl } \\
\text { go:OPT:1DU come.IMP.SG } \\
\text { "Come and let's you and I go" }
\end{array} \\
(17) \quad \begin{array}{l}
\text { kanamiyl pamiyl } \\
\text { see:OPT:1PL go:OPT:1PL } \\
\text { "Let's go and see." }
\end{array}
\end{array}
$$

The Optative verb in an Optative-Final construction functions differently from the morphologically identical, Non-Final SR2 verb as described in section The Chameleon Class, which does not have an Optative meaning. The Optative in an OptativeFinal construction also differs from the SR2 verb in that the latter marks a change of subject, whereas the subjects of the two verbs in an Optative-Final construction must be identical or overlapping, as described above. We do not designate the Optative-Final construction as a clause chain, because the Optative/SR2 form in this construction retains its canonically Final Optative meaning; it does not have the usual switch-reference function that would be expected in non-final position. Therefore, we do not include Optative-Final constructions in our counts of clause chains in this article. However, because Optative-Final constructions are a kind of clause linkage that emerges along with the earliest clause chaining by children, we do include examples of them when discussing and exemplifying the latter below (section Patterns in the Kinds of Two-Clause Chains that Children Produce).

\section{METHODOLOGY AND DESCRIPTION OF THE DATA}

The research on which the article is based was carried out in accordance with the principles of the Basel Declaration and recommendations of the Australian National University Statement on Ethical Conduct in Human Research. It was approved by the Australian National University Human Research Ethics Committee, protocol 2013/055. The article includes data from four children living in the Ku Waru-speaking Kailge region of Western Highlands, Papua New Guinea. We refer to them as Jesi, Enita, Jacklyn, and Philip.

These children can be divided into two sets based on the years when they were recorded and the different methodologies used for the two cohorts. The first cohort, Jesi and Enita, were recorded by Ku Waru field assistant John Onga between 2004 and 2006, between the ages of $1 ; 8$ and $2 ; 11$, and $1 ; 8$ and $3 ; 0$ respectively.
The sessions were conducted on an ad hoc basis, between 1 and 8 months apart during the overall period. The sessions were $37-45 \mathrm{~min}$ long. Jesi and Enita were recorded on Uher cassette recorders with Audio-Technica ATR25 microphones, in their respective homes, conversing with their parents and older siblings. Although the recording schedule was patchy, the material from Jesi and Enita is nevertheless valuable as it starts from a younger age compared to the second cohort.

The second cohort, Jacklyn and Philip, were recorded during 2013-2016, within the context of a large project on children's language socialization with dedicated funding from the Australian Research Council. Jacklyn and Philip are two of five children for whom we have longitudinal recordings during this period. These recordings were carried out by Ku Waru field assistants John Onga and Andrew Noma. Jacklyn and Philip were recorded in their homes, on a stricter recording schedule than the first cohort, for $1 \mathrm{~h}$ per month. Philip was recorded from $2 ; 2$ to $4 ; 9$, while Jacklyn was recorded from $2 ; 9$ to $4 ; 10$. Jacklyn and Philip were recorded with Olympus LS14 digital audio recorders and simultaneously filmed with Canon HFM52 digital video recorders. Jacklyn was normally recorded conversing with her mother and/or her uncle, John Onga, and Philip with his father. The samples used in this study include the entire Philip corpus (from age 2;2 to 4;9) and 1 year of the Jacklyn corpus, from 2;8 to $3 ; 8$.

After completing the recording sessions, John Onga and Andrew Noma transcribed their respective recordings by hand and translated them into their own idiosyncratic English. We asked them to render the children's utterances exactly as spoken, rather than correcting them to adult versions; and, where the children's utterances were understandable, to add a free translation into $\mathrm{Ku}$ Waru adult speech. Onga’s earlier, handwritten transcripts of Enita and Jesi were typed up by Rumsey and Merlan and drawn upon for studies of the acquisition of certain types of verb construction by Merlan and Rumsey (2017) and Rumsey (2017), and the acquisition of ergative case marking (Rumsey et al., 2013). The transcripts of Jacklyn and Philip were typed by Appen Language Services into a plain-text format. They were then processed by corpus managers Tom Honeyman and Charlotte van Tongeren in OpenRefine to fix regular scribe and typist spelling errors.

The authors of this article exported the transcripts of Jacklyn and Philip into Excel. Almost every line in the transcript corresponds to an interactional turn. Lines with verbs were coded by the authors according to the protocol below. The files pertaining to Jesi and Enita were converted from Word tables into comparable Excel sheets and coded by the authors, using the same protocol as for Jacklyn and Philip. In order to take full account of adult and other interlocutor input to the children's language learning, it would have been good to code all of the interlocutors' conversational turns along with the children's. But that was precluded by time contraints. Instead, to get a sample of that input, research assistant Siva Kalyan extracted all adult turns that immediately preceded a child's turn for six Philip and five Jacklyn files. These eleven files were selected by choosing the earliest and latest sessions for which we had coded child data, and spreading remaining sessions evenly. The adult lines were exported to Excel and coded in the same way by the authors. In 
total, the following analysis of children's and their interlocutors' speech relies on the analysis of 40 individual sessions of 3960 min each, which involved the authors' review of 32,760 lines.

Our coding protocol for this study was as follows:

1. If there were two or more verbal constructions on one line, we selected the most complex; i.e., if a line had both a twoclause chain and an independent clause, we only coded the two-clause chain in that line.

2. If an interactional turn was split over more than one line, we coded on the basis of the turn, not the typographical line (i.e., if the scribe had written a particularly long utterance over several lines, we coded the verbs as part of one utterance, not over several lines).

3. Because the differences among verb categories within the Final class were not relevant for our study of clause-chain acquisition, all verbs in the Final class were coded with a single superordinate category of Final.

4. All Medial verbs were coded as Medial. In addition, because the presence or absence of Medial suffixes is important for our study (see section The Presence vs. Absence of Medial Verb Marking on children"s Medial verbs), we coded all Medial verbs as either suffixed or non-suffixed.

5. In keeping with the discussion in section The Chameleon Class, all instances of the verbs in the Chameleon class were coded according to their syntactic position as either: Subjunctive or SR1; Optative or SR2; Future or Imminent.

6. We coded the Optative-Final construction as Optative Final.

7. As we were focused on clause chains, we did not specifically code other kinds of clause linkage such as the subordinate clause in (9). In these cases, we coded the main clause only.

All the files coded by Reed and Merlan were also checked by Rumsey, meaning that around $90 \%$ of all coding went through two coders. Inter-coder accuracy was determined by Reed and Rumsey coding the same file, and decisions compared. This was done for two files, and inter-coder accuracy was found to be, on average, 91\%. After coding was done, research assistant Siva Kalyan ran analyses and generated bar graphs using R (R Core Team, 2018) and packages tidyverse (Wickham et al., 2019), eeptools (Knowles, 2019), openxlsx (Schauberger and Walker, 2019), and readxl (Wickham and Bryan, 2019).

\section{THE EMERGENCE OF CLAUSE CHAINING}

In this section we will trace the emergence of clause chaining among the four target children in our study, and later in section Adults' and Older Children's Speech to the Target Children in $\mathrm{Ku}$ Waru, compare it with the incidence of clause chaining in the speech by adults to the children. As we shall see, there is considerable variation among the children in the ages at which clause chaining first emerges, and at which various kinds of chains emerge and develop. However, there are some quite consistent patterns regarding the order in which kinds of chains emerge and develop.
Before we discuss these results, it is important to address the issue of prompting and imitation. As is probably true of all fairly extensive child language corpora, some of the Ku Waru children's utterances in our corpus are partial or full repetitions of what has been said to them by an adult in the previous turn or a few turns back, sometimes in response to explicit prompting in the form "Say "_.'." It is important to take careful account of this, especially when looking for the earliest instances of given clausechain types. To that end, we examined all instances of clause chains in the children's speech within their interactional contexts, coding them as either "prompted" or "unprompted," where "prompted" is a cover term that includes not only responses to explicit prompts, but any utterances which fully or partially reproduced what has been said to the child within the previous two turns. The results are as follows:

- There is no prompting in any of the clause chains from Jesi or Enita.

- There is very little prompting in the clause chains from Philip. His first two-clause chains at $2 ; 7$ and $2 ; 8$ are unprompted. At $3 ; 0$, the ratio of unprompted to prompted two-clause chains is $1 / 1$; at $3 ; 1-9 / 2$; at $3 ; 7-6 / 5$; at $3 ; 9-6 / 1$. None of the clause chains in any of the other months is prompted.

- The incidence of prompting is much higher in the samples from Jacklyn, with the majority of her two-clause chains from $2 ; 8$ to $2 ; 11$ being prompted ones. The incidence of prompted two-clause chains drops off sharply after $3 ; 2$, with none after $3 ; 3^{10}$.

In the remainder of this article, we have not attempted to take account of the difference between prompted and unprompted utterances, or to exclude the former. That would have been unfeasible given the size of the corpus. The aforementioned qualitative review reassures us that prompting is not excessive. There is one exception to this which pertains to Jacklyn's first two-clause chains, which we discuss in the next section.

\section{Two-Clause Chains}

As a first step, let us consider the emergence of clause chaining per se. This is shown in Figure 1. Note that in this graph, "Chain length: 1 " denotes an independent clause [as in [6] and [13]]. In this graph and all the others in this article, the numbers in the middle of each bar indicate the sample size. Note that, in order to increase the visibility of the very small bands at the top of the bars in Figure 1, only the top 35\% of the range is shown. Other graphs throughout the paper have been similarly magnified where possible. In every case the lower portions of the bars are to be read as extending the leftmost category all the way down to $0 \%$.

Two-clause chains are first attested from Jesi at 1;9 and from Enita at 2;0. For Philip they do not appear until considerably later, at 2;7. This is a reliable finding, given the availability of four samples for Philip at younger ages going back to 2;2 which include no two-clause chains. Jacklyn produces only two twoclause chains at $2 ; 8$, both of which are prompted. We chose to

\footnotetext{
${ }^{10}$ The ratios of unprompted two-clause chains to prompted ones in the months when the latter occur in Jacklyn's speech are: $2 ; 6-0 / 2,2 ; 8-4 / 5,2 ; 9-7 / 11,2 ; 11-7 / 4$, $3 ; 0-5 / 3,3 ; 1-15 / 1$.
} 


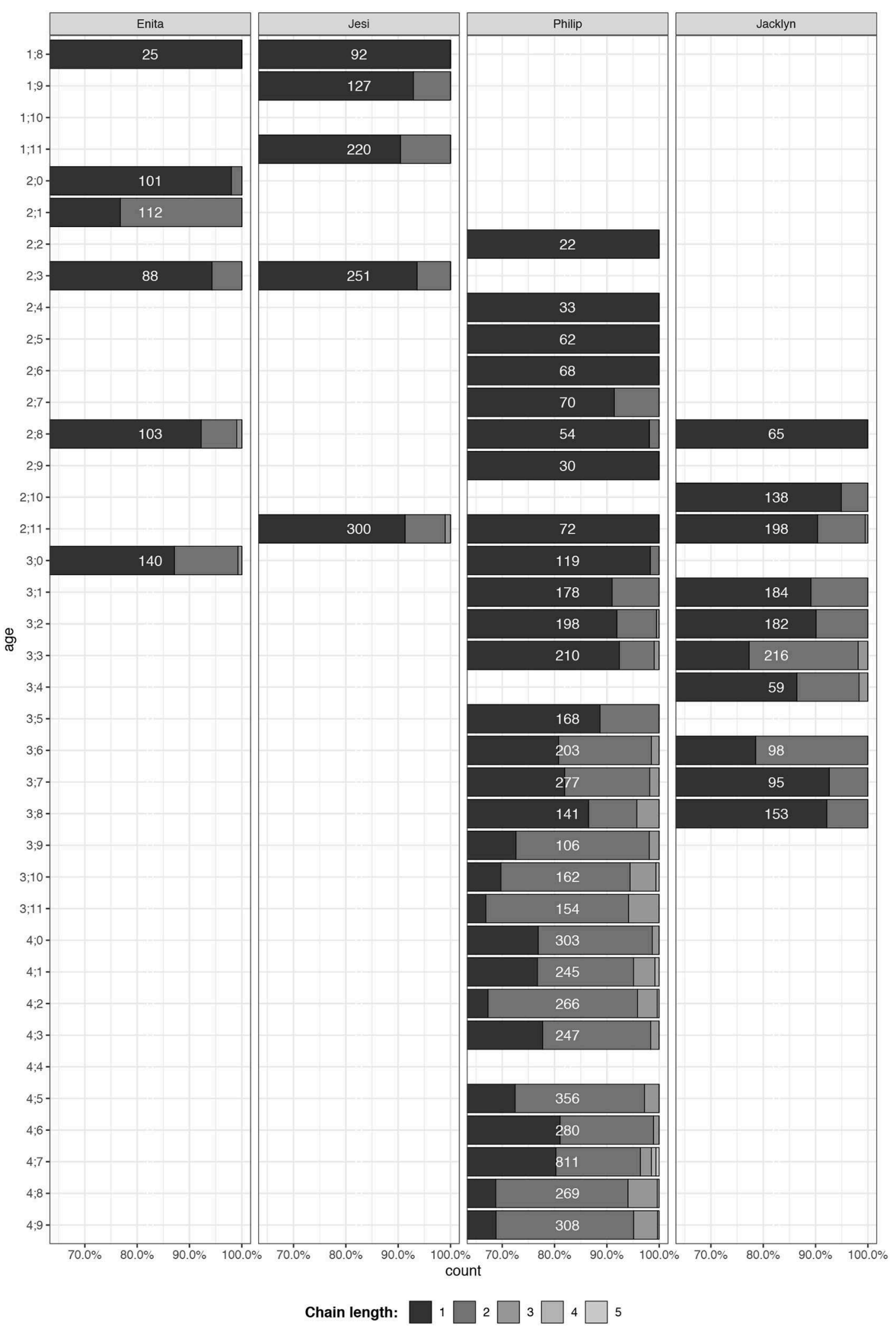

FIGURE 1 | Lengths of clause chains in longitudinal samples from four Ku Waru children. 
omit these from Figure 1, as their inclusion would have given a misleading impression of the age at which the ability to produce such chains is first attested in her speech. For each of the other three children, the first attested instances of two-clause chains are unprompted. By the age of 3;1 (and earlier for Jesi and Enita) all four children are using two-clause chains regularly, albeit much less frequently than independent clauses. Of note, the very high number of two-clause chains for Enita at age 2;1 is because, in a fit of enthusiasm over tossing coins, she repeats the same two-clause chain (19) 23 times in the course of the session.

\section{Patterns in the Kinds of Two-Clause Chains that Children Produce}

In section Two-Clause Chains we began to discuss the emergence of clause chaining solely in terms of their length. Bearing in mind from section Relevant Aspects of Ku Waru Grammar that there are four different inflections that can occur in non-final position and hence make up a chain, we will now consider which of those inflections appear in the children's earliest attested clause chains, and how they are used. As data for that examination, the first five instances of two-clause constructions to appear in each of the four children's speech are shown in (18)- $(37)^{11}$. Note that, for reasons discussed in section The Optative-Final Construction as a Clause Chain?, in addition to clause chains proper, this sample includes two instances of the Optative-Final construction, (21) and (25). We include these constructions to show that they first emerge at around the same time as clause chains.
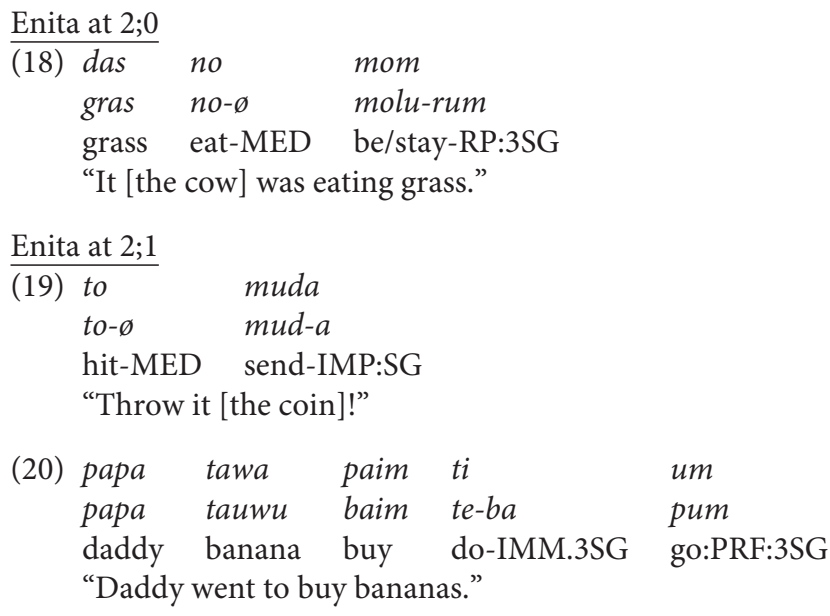

Enita at $2 ; 3$

\begin{tabular}{|c|c|c|}
\hline \multirow[t]{3}{*}{ (21) } & pabla & $w a$ \\
\hline & pabiyl & $w a$ \\
\hline & $\begin{array}{l}\text { go:OPT:1DU } \\
\text { "Come and let }\end{array}$ & $\begin{array}{l}\text { come:IMP:SG } \\
\text { go." }\end{array}$ \\
\hline
\end{tabular}

\footnotetext{
${ }^{11}$ Here and below, in all the examples where there is a second line of Ku Waru beneath the top line, the second line is one that has been provided by our Ku Waruspeaking field assistants as what they take to be the adult equivalent of the child's utterance. We have only accepted these "equivalent" forms as such when they seem phonetically similar enough to the posited adult forms and/or when they match up with responses by the caregivers in their responses to the children. As can be seen below, the posited adult forms are generally quite similar to the children's, the main exceptions being cases where the children use "incorrect" verb forms, which are changed to contextually appropriate adult ones, e.g., (26), (37), and (39).
}
(22) kela $p a$
kela- $\varnothing$
$p a$
quit-MED go:IMP:SG
"Go away!", "Leave!."

Jesi at $1 ; 11$
(23) nok mului
nosu-k molu- $i$
keep-MED.2 be/stay-JUS
"Keep it."
(24) to muda
to- $\varnothing \quad$ mud- $a$
hit/do-MED send-IMP:SG
"Throw it."

(25) tabiyl wa

hit/do:OPT:2DU come:IMP:SG

"Come and let's you and I do it [catch it]."
(26) $m e k^{12} \quad$ pabi
me-p $p a b-i$
carry-MED.1 go:OPT:1SG-Q
"Shall I take you?"
(27) $m e-k \quad u i-o$
carry-MED-2 come:JUS-VOC
"Please bring it"

Philip at $2 ; 7$
(28) alte- $k^{13}$
te
do.again-MED.2 do:IMP:SG
"Do it again."

(29) alte

$\begin{array}{ll}\text { alte- } \varnothing & \text { nya } \\ \text { do.again-MED } & \text { say:IMP:SG }\end{array}$

"Say it again."

Philip at $2 ; 8$

\begin{tabular}{|c|c|c|}
\hline \multirow[t]{4}{*}{ (30) } & alse & te \\
\hline & alte-ø & $t e-a b$ \\
\hline & do.again-MED & do-OPT:1SG \\
\hline & "Shall I do it aga & n?” \\
\hline
\end{tabular}

Philip at 3;0

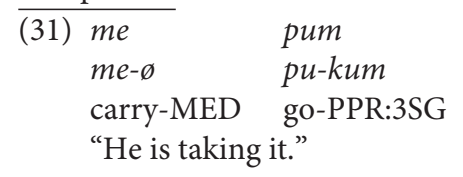

\footnotetext{
${ }^{12}$ This is an incorrect second-person form, which was corrected to first-person mep by our field assistant as shown in the second line.

${ }^{13}$ There were four other instances in this session of an alternative version of this same expression without the Medial suffix - $k$ on the first verb, i.e., ate te (in one instance pronounced as ati ti). As we shall see in section The Presence vs. Absence of Medial Verb Marking, omission of the suffixes on Medial verbs is quite common in children's speech.
} 

(32) gisi
lkisi-ø
$u i$
run/do.quickly-MED come:JUS
"Come quickly."

Jacklyn at $2 ; 10$

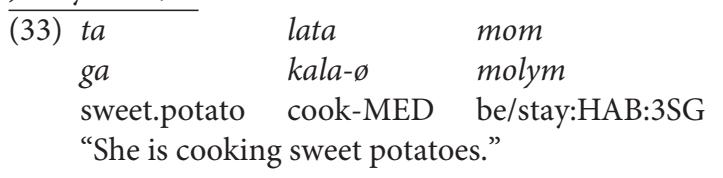

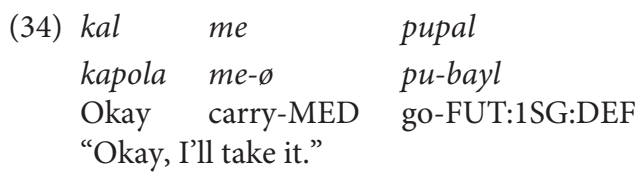
(35) na pu lep
na $p u-\varnothing \quad l y i-b u$
I go-MED get-FUT.1SG
"I'll go and get it."

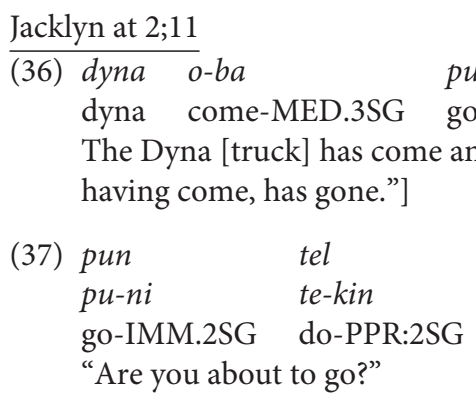

Now let us consider the kinds of verbs that are found in the non-final clauses of these two-clause chains, and the kinds of meanings that are expressed by the combination of those clauses with the final ones. Among the 20 non-final clauses in the sample, the verbs in two of them are of the Imminent inflection, expressing imminence or intentionality as described in section The Chameleon Class. Those are in examples (20) - "Daddy went in order to buy bananas"-and (37)_- "Are you about to go/intending to go." Two of the other verbs in non-final clauses are Optative ones, occurring in the Optative-Final construction described in section The Optative-Final Construction as a Clause Chain?, which is used for proposing a joint action. Those are examples (21) — “Come and let's go"—and (25)_- "Come and let's do it."

In the other 16 two-clause chains in the sample, the verbs in the non-final clauses are all Medial ones. But interestingly, only a small minority of them are used for what is often taken to be the prototypical function of clause chains, i.e., predicating a series of events in sequence (see section Introduction). Instead, the verb combinations in 14 of those 16 clause chains are grammaticalized or lexicalized ones of the kinds discussed in section Clause Chains vs. Serial Verb Constructions in Ku Waru which jointly refer to a single event. The types of combinations involved are:

- the verb mol- used in final position with a durative aspectual meaning in (18), (23), and (33);
- the verb to- (literally "hit") used in a lexicalized combination with the verb mud ("send," "dispatch") to mean "throw" in (19) and (24);

- the verb alt-, used in adverbial function with its usual meaning of “(do) again" in (28), (29) and (30);

- the verb lkis- (literally "run") used in non-final position with one of its common, adverbial functions there to mean "do quickly" in (32);

- the verb me- "carry" used non-finally in lexicalized combinations with the verb $p u$ - "go" to mean "take" in (26), (31), and (34), and in combination with the verb $o$ "come" to mean "bring" in (27);

- the verb kel- "quit" used in combination with verb pu-"go" to mean "Go away," "Leave" in (22).

In the whole sample of 20 two-clause constructions (18 of which are clause chains) there are only two that refer to two distinct events in sequence. Both of those examples are by Jacklyn, at 2;10 and 2;11. They are: (35) "I'll go and get it" (literally "I, having gone, will get it.") and (36) “The Dyna [truck] has come and gone." All the rest of the Ku Waru children's first two-clause chains are lexically specific ones that refer to a single event.

There is a parallel here with English-speaking children's acquisition of multi-clause sentences (Diessel, 2004). Just as English children first learn the structure of multi-clause constructions through common, lexically specific exemplars that refer to single events, Ku Waru children learn the structure of clause chains by recourse to common, lexically specific clause chains that refer to single events. All of the verb sequences in the utterances examined here are very frequently-occurring ones in the speech of adults and older children, as evidenced by Rumsey and Merlan's experience with the language.

To continue investigating the emergence of clause chaining, let us now consider which of the four verb types that occur in non-final position are used by children in their clause chains (Figure 2).

Strikingly, as shown in Figure 2, there is not a single instance of SR2 in any of the children's two-clause chains, and there are only three instances of SR1 (all from Philip at 4;7). The overwhelming majority of verbs that appear in penultimate position in these data are Medial and Imminent ones. Figure 2 also shows that, for all four children, Medial verbs are the first verbs to emerge in non-final position. Imminent verbs follow, emerging at ages ranging from $1 ; 11$ for Jesi to $3 ; 1$ for Philip. Interestingly, once they have emerged, the ratio of Medial verbs to Imminent verbs remains relatively constant for all the children across the sampled age ranges, or, at least, without any clear directionality of change.

Is the children's delay in using Imminent, SR1, and SR2 verbs due to their delay in acquisition of the form of these verbs, or to delay in acquisition of their function in non-final position? To investigate this, we looked at when the parallel finalposition inflections Future, Subjunctive and Optative emerged in the children's speech. If this is roughly simultaneous with their emergence in non-final postion, it could be taken to suggest that the hurdle for the children is acquisition of the 


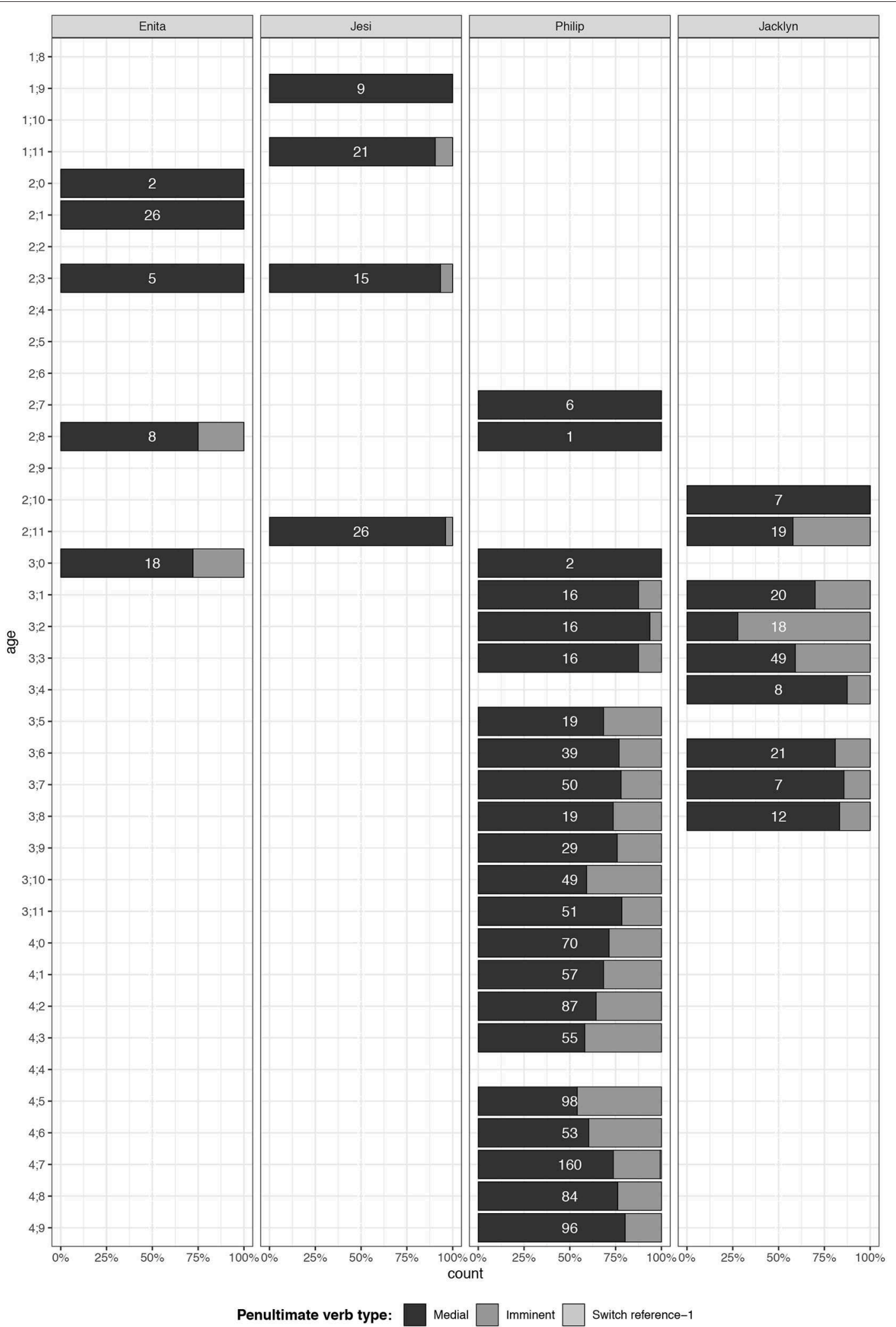

FIGURE 2 | Proportions of verb types in the next-to-last clauses of the children's clause chains. 


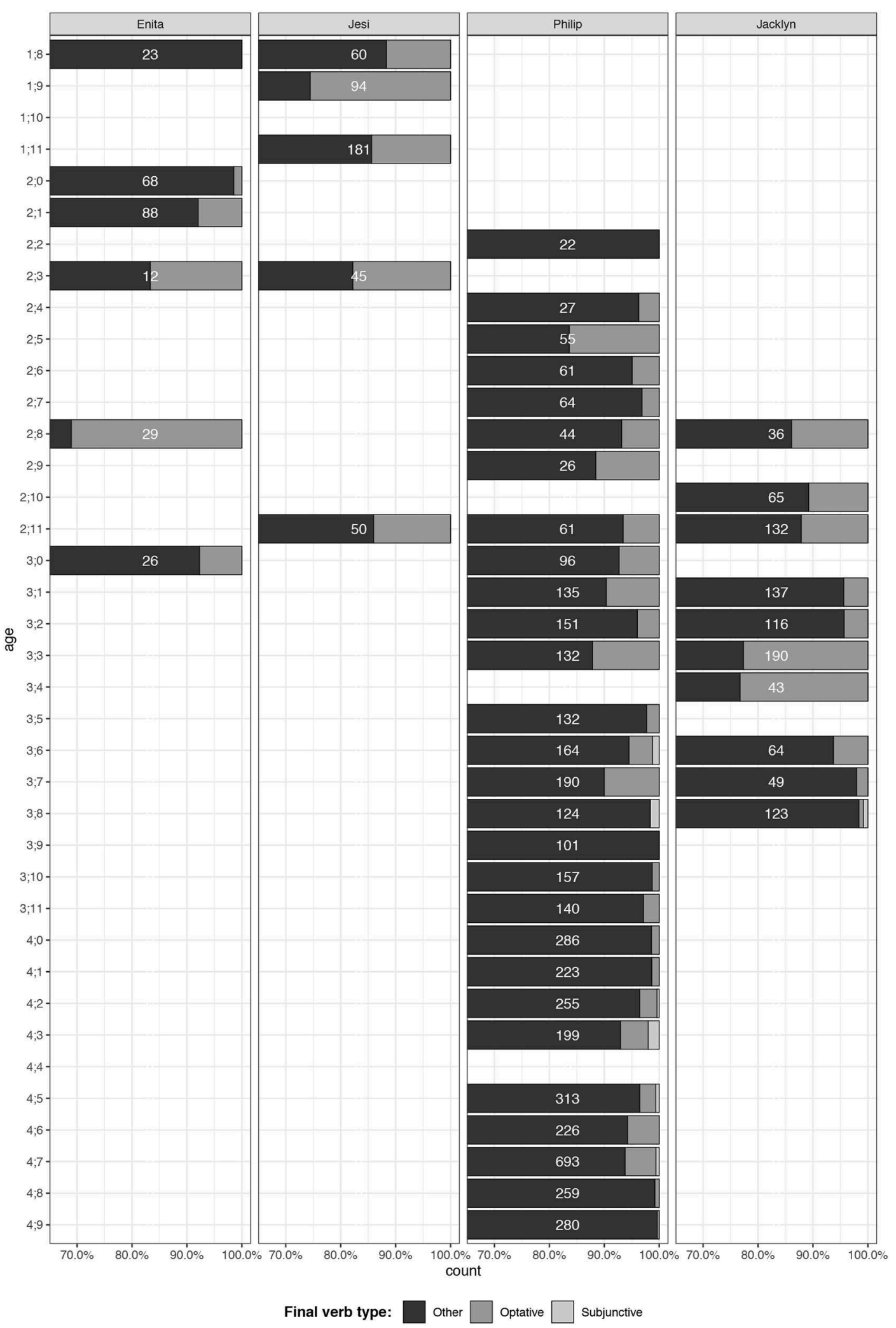

FIGURE 3 | Proportions of Optative and Subjunctive vs. other clause chain-final verbs in the children's speech. 
forms. If, however, there is a discrepancy between the emergence of the forms in final vs. non-final positions, it suggests that the hurdle is the acquisition of the function. Figure 3 shows the results of our comparison. Note that in Figure 3, "Final" denotes all the verb categories that are designated that way in the top row of Table 1, as opposed to Future, Subjunctive and Optative verbs which are the object of our comparison in this particular analysis.

As can be seen from Figure 3, Optative verbs are fairly wellattested, occurring in the earliest samples from two of the four children, and remaining fairly frequent for the rest of their age ranges. Perhaps rather surprisingly, the proportion of Optatives does drop off noticeably for Philip after 3;3 and for Jacklyn after $3 ; 4$, but this can perhaps be related to a concomitant increase in the use of less common Final-class verb inflections such as Habitual and Remote Past. Note that, in contrast to the Optative, the Subjunctive emerges much later-at 3;8 for Jacklyn and 3;6 for Philip-and remains very infrequent right through to the end of Philip's range at 4:9.

Comparing Figures 2, 3, it is clear that the children's low production of SR1 forms and absence of SR2 forms is not based on any inability to learn their forms. The Optative is used infinitely more frequently then its SR2 counterpart, given that no SR2 forms are produced at all. Uses of the Subjunctive, although rare, greatly outnumber the three instances of its counterpart SR1 (by Philip at 4;7). Before drawing final conclusions, we consider Future and Imminent, the other pair of inflections that involve identical forms but different functions when in final and non-final position.

The incidence of Imminent verbs in two-clause chains has been displayed and discussed above in relation to Figure 2. The overall incidence of Future verbs in the child corpus, and its frequency relative to that of the Imminent class, is shown, among other information, in Figure 4. To produce this graph, we determined the overall frequency of any clausal construction in the data that included a verb (independent clauses, the OptativeFinal construction, and clause chains). The key of Figure 4 shows the five most common constructions. Three of these are independent clauses: Other final (denoting all verbs in the Final class with the exception of Future ones); Future, as a predicate in independent clauses; and Optative, as a predicate in independent clauses. The other two most common constructions are clause chains, namely the chain Medial-Final (where Final denotes any verb of that class); and the chain Imminent-Final (where Final denotes any verb of that class). "Other" denotes constructions that do not fall into these five categories, such as Medial-Future. The final designation in the key is "Uncoded final." For some of the Enita and Jesi sessions, some of the verbs in singleclause utterances were not extracted from the transcripts and hence did not feature in the data that we coded for this project. However, while the exact utterances were not extracted and hence not coded for Final inflection, the number of independent clauses was counted. These numbers are included as "Uncoded Final" verbs.

Figure 4 shows that Future verbs emerge very early in all the children's speech. They are present in the first samples from three of them-Enita and Jesi at $1 ; 8$, and Jacklyn at 2;8-and in all the subsequent samples from each of them, in varying proportions. Despite this early emergence, for all the children there is a considerable delay before they begin to use Futureform verbs in non-final position as the Imminent (Figure 2). Despite using the Future at $2 ; 4$, Philip does not begin to use this form in non-final position in a clause chain until 3;5. In the transcripts we have, which go up to $2 ; 11$, Jesi never produces any Imminent-Final clause chains, despite using the Future as early as $1 ; 9$.

From the above discussion of Figures 2-4, a conclusion we draw is that the children's learning of the Optative, Subjunctive and Future forms provides part of the basis on which they master the grammar of the two switch-reference inflections and the Imminent inflection, by putting the same forms to different uses in non-final position, as in adult speech. The other, more difficult prerequisite for the mastery of the switch-reference categories which may delay their acquisition is the cognitive capacity to hold two distinct person/number categories and/or events in mind at once, in order to treat them relationally, one with respect to the other.

\section{The Emergence of Longer Chains}

Returning to Figure 1, three-clause chains begin to emerge from all the children between the ages of $2 ; 8$ and $3 ; 3$. They remain very infrequent for Enita, Jesi and Jacklyn thoughout the periods for which we have samples for these children - up until 3;0, 2;11, and $3 ; 8$, respectively. In all of those samples, the proportion of threeclause chains never exceeds $2 \%$ of the total number of clause chains. The same is true of Philip up until the age of $3 ; 8$ when the proportion of three-clause chains increases to about $4 \%$, and stays between 3 and $5 \%$ in most of the rest of the samples for him, up to $4 ; 9$.

The first instances of three-clause chains from each of the children are shown in (38)-(48). These include the only attested three-clause chains for Enita and Jesi, and the first three of them from Philip and Jacklyn.

Enita at $2 ; 8$

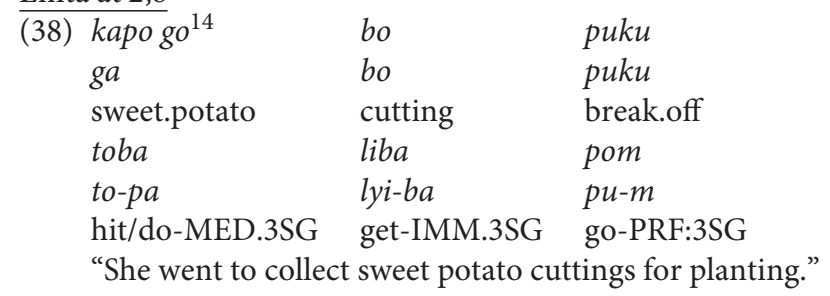

Enita at $3 ; 0$
(39) pup
$p u-p$
lip
lyi-p
purun $^{15}$
go-MED.1 get-MED.1
"I will go get it and go."
$p u-b u$
go-FUT.1SG

14 Though the overall sense of this utterance by Enita seemed clear to our field
assistants within its context, it is unclear which of the words kapo go corresponds
to ga "sweet potato." The word kapu in adult speech means "big," so it could be that
the overall sense of Enita's kapo go bo is to be taken as "big sweet potato cuttings."
${ }^{15}$ This verb has "incorrect" person and tense marking, -run, which in adult speech
is second person singular remote past (as shown in Table 1). Given the first-person
subject marking on the preceding Medial verbs and the context of use, our field
assistants took Enita's intended meaning to be "I will go and get it' and accordingly
corrected the final verb to pubu. 


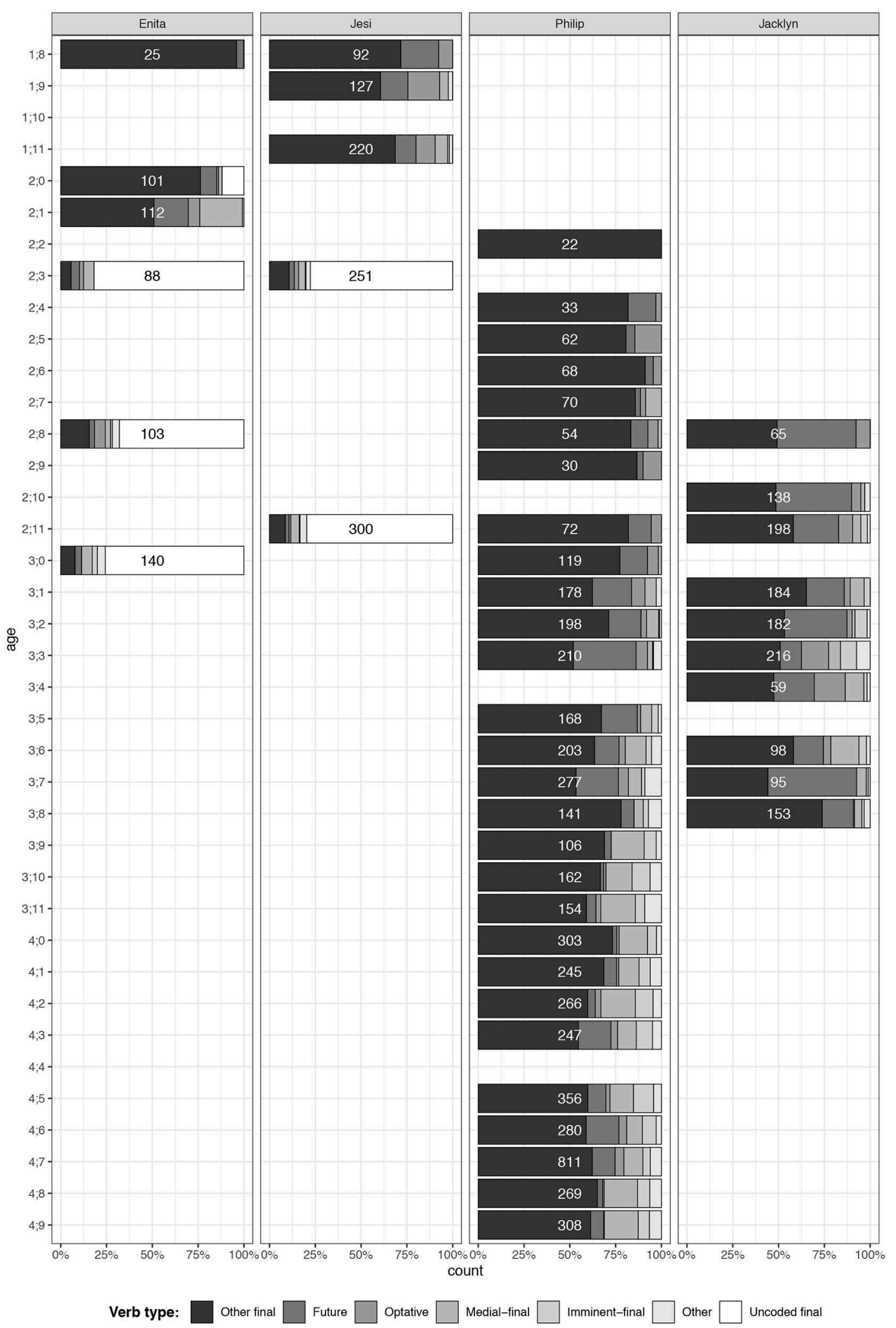

FIGURE 4 | Incidence in the children's speech of common clause chain types. 
Jesi at $2 ; 11$
(40) $t i \quad k a k$
ti kal-kuk
nok
$m u k u^{16}$
one cook-MED.2SG eat-MED.2SG be/stay-JUS
"Cook one [sweet potato] and eat it."

(41) top

$\begin{array}{lll}\text { top } & \text { koip } & \text { nob } \\ \text { to- } p & \text { koi- } p & \text { no-bu } \\ \text { hit/do-MED.1 } & \text { roast-MED.1 } & \text { eat-FUT.1SG } \\ \text { "I'll kill, roast and eat them [the puppies]." }\end{array}$

(42) alni

$a k i-y l-n$

to koiya

that-DEF-ERG

to- $\varnothing$

koi-pa

sirim

si-rim

give-RP:3SG

"That one [my uncle] killed it [a dog], roasted it and gave it [to me].”

Philip at $3 ; 3$

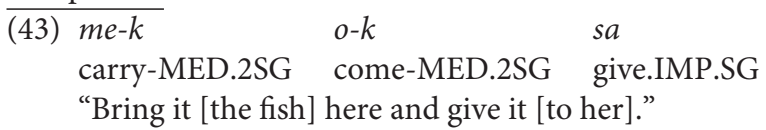

Philip at $3 ; 6$

\begin{tabular}{|c|c|c|c|c|}
\hline \multirow[t]{6}{*}{$(44)$} & 4) $n a$ & kung & kap & to \\
\hline & $n a$ & kung & kap & to- $\varnothing$ \\
\hline & I & pig & big & hit(/kill)-MED \\
\hline & $k o i$ & nobal & & \\
\hline & $k o i-\varnothing$ & no-bayl & & \\
\hline & roast-MED & eat-FUT.1SG:DEF & & \\
\hline
\end{tabular}

(45) jepoya

Jekob Poya

to me

(boy's name)

to- $\varnothing \quad m e-\varnothing$

umal

um-ayl

come-PRF:3SG-DEF

"Jekob Poya killed it and brought it home."

Jacklyn at $3 ; 3$

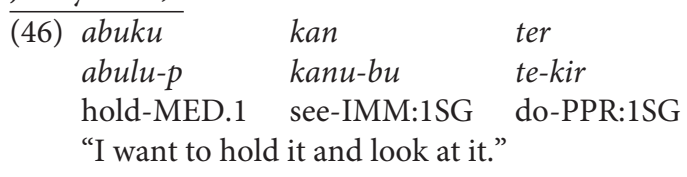

(47) is

$\begin{array}{lll}\text { is } & \begin{array}{c}\text { abulup } \\ \text { abolu-p }\end{array} & \text { mulab } \\ \text { isi-ø } & \text { mol-ab } \\ \text { doing.like.this-MED } & \text { hold-MED.1 } & \text { be/stay-OPT.1SG } \\ \text { "I'll keep holding it like this." } & \end{array}$

\footnotetext{
${ }^{16}$ This three-clause chain was actually embedded with a reported speech construction:

\begin{tabular}{|c|c|c|c|c|c|}
\hline na & $t i$ & $k a k$ & nok & muku & $n i$ \\
\hline na & $t i$ & $k a l-k u k$ & $n o-k$ & molui & $n y i-m$ \\
\hline I & one & cook-MED.2SG & eat-MED.2SG & be/stay:JUS & say-PRF.3SG \\
\hline
\end{tabular}
}

(48) to-ø pora si-pa lim hit/do-MED finish give-MED.3SG be:PRF.3SG "She finished doing it [playing] and stayed there."

Four- and five-clause chains are attested only in the speech of Philip, during an age range for which we do not have samples from any of the other children: 3;10-4;9. Of note, sentences (50) and (52) were spoken by Philip when looking through a wordless picture-story book that he was being shown by field assistant Andrew Noma. These sentences are in reference to a series of pictures in which a man had fallen asleep beside his hat, which is then stolen by an eagle who swoops down on it, grabs it in its talons, and flies away with it. Examples of four-clause chains are shown in (49) through (51).

\begin{tabular}{|c|c|c|c|c|}
\hline \multicolumn{5}{|c|}{ Philip at $4 ; 7$} \\
\hline \multirow[t]{7}{*}{ (49) } & ilyi & \multicolumn{2}{|l|}{$o b a$} & ite \\
\hline & ilyi & \multicolumn{2}{|c|}{$o-b a$} & ite- $\varnothing$ \\
\hline & that one & \multirow{2}{*}{\multicolumn{2}{|c|}{$\begin{array}{l}\text { come-MED.3SG } \\
\text { tirim }\end{array}$}} & do.like.this-MED \\
\hline & puba & & & \\
\hline & $p u-b a$ & \multicolumn{2}{|c|}{ tirim } & \\
\hline & go-IMM:3S & \multicolumn{2}{|c|}{ do:RP:3SG } & \\
\hline & "That one $[\varepsilon$ & rl] had com & like this a & and was about to go.' \\
\hline \multirow[t]{7}{*}{$(50)$} & wana & kanuwa & le & me \\
\hline & wanya & kanu-wa & $l y i-\varnothing$ & $m e-\emptyset$ \\
\hline & hat & that-DEF & get-MED & carry-MED \\
\hline & pulka & wis & niring & \\
\hline & $p u-l k a$ & wis & nyi-ring & \\
\hline & go-SR1:1/3 & hey & say-RP:2 & /3PL \\
\hline & $\begin{array}{l}\text { "It [the eagl } \\
\text { they said 'H }\end{array}$ & , having ta & $n$ the hat & and carried it away, \\
\hline
\end{tabular}

Philip at $4 ; 8$

\begin{tabular}{|c|c|c|c|}
\hline \multirow[t]{7}{*}{$\overline{(51)}$} & mo & top & abulup \\
\hline & mo & to-p & abolu-p \\
\hline & conceal & hit/do-MED.1 & hold-MED.1 \\
\hline & me & purubulal & \\
\hline & $m e-\varnothing$ & pu-rubul-ayl & \\
\hline & carry-MED & go-RP:1PL-DEF & \\
\hline & "We hid it a & d took it away.” & \\
\hline
\end{tabular}

Examples of five-clause chains are shown in (52) and (53).

Philip at $4 ; 7$

\begin{tabular}{|c|c|c|c|}
\hline \multirow[t]{5}{*}{$(52)$} & wana & torulupa & lyipa \\
\hline & wanya & torulu-pa & lyi-pa \\
\hline & hat & grab-MED.3SG & get-MED.3SG \\
\hline & mера & lkisa & $u m$ \\
\hline & $m e-p a$ & lkisi-ø & $u m$ \\
\hline
\end{tabular}

carry-MED.3SG run/do.quickly-MED come.PRF.3SG "It [the eagle], having grabbed the hat, took it away and swiftly brought it."

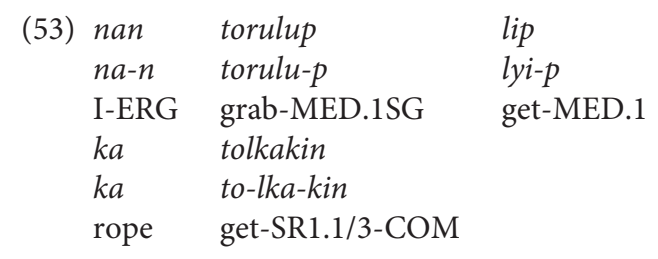




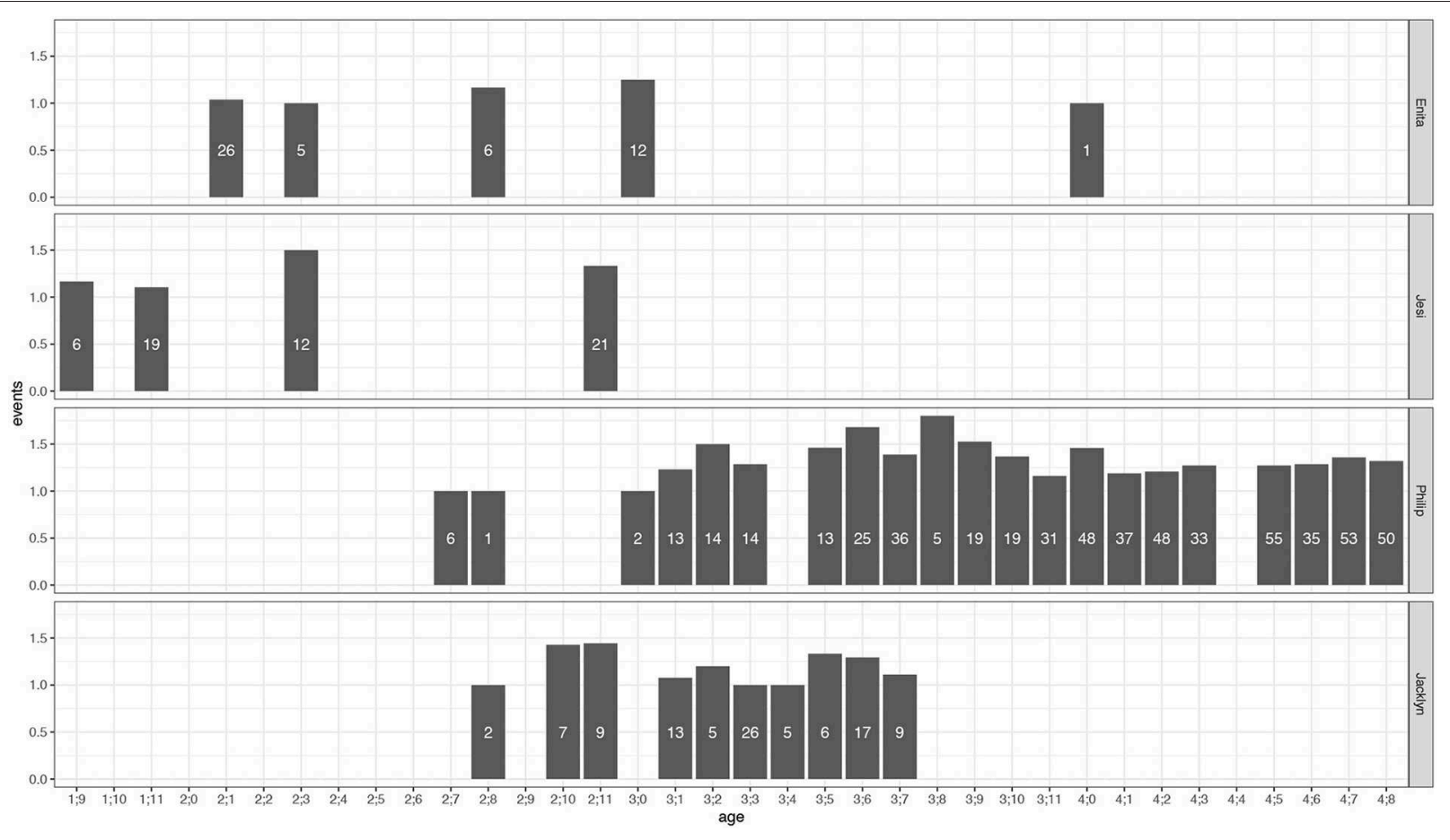

FIGURE 5 | Mean number of events referred to in the children's two-clause chains.

no
no daip te
water/river daip te- $\quad$ dive do-MED
$\begin{aligned} & \text { mulurum } \\ & \text { mulu-rum }\end{aligned}$
be/stay-RP:3SG
"When I grabbed it and tied it up he was diving into
the river."

Examples (38-53) are all fully adult-like in their syntax, but have some morphological errors as evident from the corrections in gloss lines and relevant footnotes. The three-, four-, and fiveclause chains that the children go on to produce after the intial two-clause stage almost all make use only of verb inflections that the children are already producing in their two-clause chains. The only exception to this is switch-reference marking, which emerges only in the speech of Philip, at $4 ; 7$, as exemplified by (50) and (53). Its emergence at that stage is consistent with the surmise we made in section Patterns in the Kinds of Two-Clause Chains That Children Produce that the children's learning of the SR1, SR2, and Imminent inflections is supported by their prior learning of the formally identical Subjunctive, Optative, and Future ones. For example, Philip first used the Subjunctive inflection at 3;6 (as shown in Figure 3), long before he first uses its counterpart SR1 inflection at age 4;7.

\section{Clause Chains and Event Structure in the Children's Speech}

In section Patterns in the Kinds of Two-Clause Chains That Children Produce we discussed the first five two-clause constructions to be used by each of the four children, and showed that 18 of these were clause chains and two were instances of the Optative-Final construction. We showed that only two out of the eighteen clause chains $(11 \%)$ were used for what is often taken to be the canonical function of clause chains: reference to multiple events in sequence. The rest of the 18 clause chains are particular grammaticalized or lexicalized constructions for expressing meanings such as durative aspect, intentionality, or event qualifications such as "do quickly" or "do again," which all refer to single events. Given that such regular pairings are probably easier for children to learn than novel clause chains referring to events in sequence, the paucity of the latter in those early clause-chain productions raises the question of whether there might be a trend in the children's later speech toward multievent reference in chains of given lengths. To test that hypothesis, we looked through all of the children's two-clause chains, coded them as one-event or two-event ones, and computed the average number for each sample. The results are shown in Figure 5.

As can be seen in Figure 5, there is no consistent increase or other big change across time in the average number of events referred to in the children's two-clause chains. Given that result, the question arises of whether there might be more of a tendency for multiple events to be referred to in the children's threeto five-clause chains. Might there be a tendency for the ratio of events-to-clauses to increase over time when we consider longer chains?

To address those questions, we focused exclusively on Philip, as his are the only samples with significant numbers of three-clause chains, and the only ones with any four- or fiveclause chains. We inspected all of those three- to five-clause 


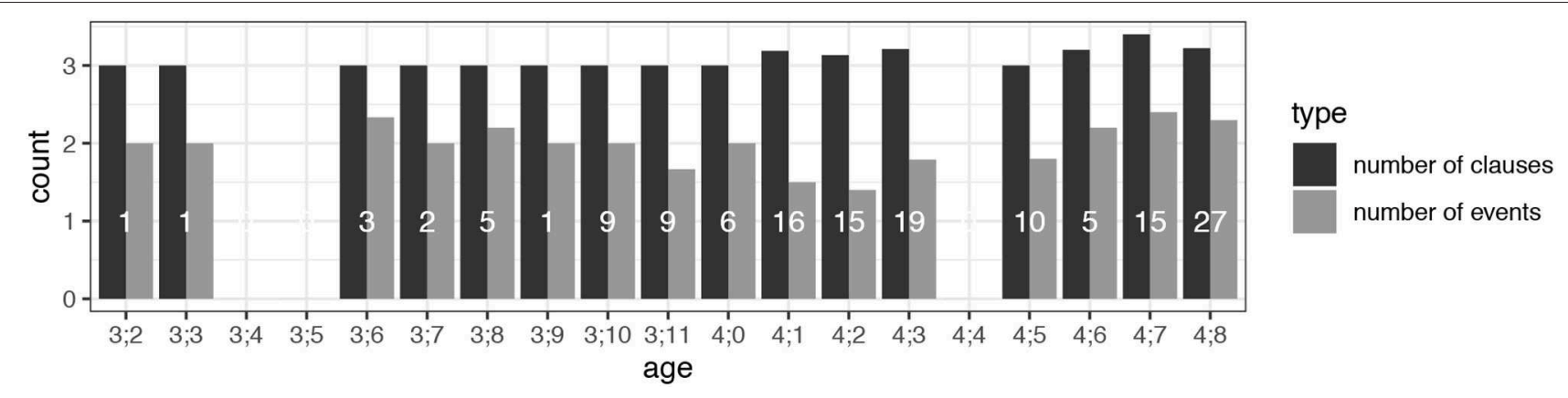

FIGURE 6 | Mean lengths of chains with three or more clauses in the speech of Philip, and mean numbers of events referred to in them.

chains, coded them for the number of clauses and the number of events in each, and computed the mean for each month in each sample. The results are shown in Figure 6.

Paralleling the results for two-clause chains in Figure 5, the ratio of number of events to number of clauses remains fairly constant throughout the sample in Figure 6, especially in the first 2 months and the last four. Even as the mean chain length increases in most of the months after 4;0, there is no corresponding increase in the ratio of events to clauses.

\section{The Presence vs. Absence of Medial Verb Marking}

Before comparing the children's clause chain production to their adult interlocutors', we consider the phenomenon of dropping of Medial verb morphology. As introduced in section Presence vs. Absence of Medial Verb Marking, Ku Waru Medial verbs sometimes occur without the Medial suffixes in adult speech. As can be seen in examples (18)-(35), the unsuffixed forms are frequent in most of the children's early speech. The following analyses compare the children's production of Medial verbs with specific reference to whether or not they are suffixed. This is of interest, as the Ku Waru children's use of Medial/medial verbs differs sharply from that in Nungon, another Trans New Guinea language (Sarvasy, 2019). We will return to this shortly.

As shown in Figure 7, the children differ greatly in their use or non-use of Medial suffixes over time. Enita has a fairly clear pattern in which she moves from using unsuffixed forms to suffixed ones. Jesi, on the other hand, shows a relatively high proportion of the suffixes from the beginning of his use of Medial verbs at $1 ; 9$, and no clear overall pattern of increase or decrease in the use of the suffixes over the next 14 months. The same is true of Jacklyn's incidence of suffixed forms over the 13-month span of samples. Over the much longer timespan for which there are samples from Philip, he shows an overall increase in suffixation, with rates at or above $50 \%$ from $4 ; 2$ to $4 ; 9$.

In assessing the significance of these findings one must bear in mind that they pertain to only a small subset of the utterances counted in Figure 1, namely the ones consisting of clause chains which include Medial verbs. That means that the sample size for each month in the counts for Figure 7 (as shown in the middle of each bar) is much smaller than for each of the corresponding samples shown in Figure 1. This no doubt accounts in part for the apparently greater degree of random fluctuation in Medial suffixation from month to month in Figure 7.

Very occasionally the $\mathrm{Ku}$ Waru children in our sample use Medial verbs in independent clauses (that is, in an utterance that contains only one verb; not a clause chain). This is relevant to note in connection with discussions in the child language literature of an "optional infinitive stage" of language acquisition, in which infinitives function as predicates in independent clauses (Rizzi, 1994; Hoekstra and Hyams, 1998; Wexler, 2011; Grinstead et al., 2014; Sarvasy, 2019). Across the entire Ku Waru child corpus for this study, such independent Medial verbs account for only $0.59 \%$ of the number of children's verbs ${ }^{17}$. Given this very low frequency, the use of independent Medial verbs (whether suffixed or unsuffixed) cannot be said to be a stage in Ku Waru children's acquisition of the language. In this respect our results regarding $\mathrm{Ku}$ Waru children's acquisition of Medial verbswhether independent, or dependent but without suffixes (see section Presence vs. Absence of Medial Verb Marking)-differ from those in the root-infinitive literature.

In addition, clauses with standalone or chain-final Medial verbs account for only $0.46 \%$ of all adult verbal utterances in our corpus, and are regarded by $\mathrm{Ku}$ Waru speakers as incorrect or incomplete. This contrasts sharply with another Trans New Guinea language, Nungon, where it is relatively common for chains to end in a Medial verb. Sarvasy (personal communication) found that in Nungon adult narratives over $3 \mathrm{~min}$ in length, $4-20 \%$ of all clause chains end in a Nungon medial verb. Of note, though, in Nungon, medially marked verbs in final position have grammatical and discourse-related functions, including functioning as imperatives, summarizing a previous clause chain, or marking perfect aspect (Sarvasy, 2015, p. 679). Ku Waru has no such strategies which would license chains ending in Medial verbs. We now turn to adult childdirected speech, showing a slice of the input that children receive.

\footnotetext{
${ }^{17} \mathrm{~A}$ referee has questioned whether unsuffixed Medial verbs when occurring in non-final position might also be considered candidates for "optional infinitive" status. We think not, because, as discussed above, even unsuffixed verbs in $\mathrm{Ku}$ Waru are positively specified as Medial because they are the only verbs in Ku Waru that may optionally occur in unsuffixed form. Accordingly, when occurring in nonfinal position, even when unsuffixed, these verbs, and the clauses in which they occur, are syntactically dependent rather than independent.
} 


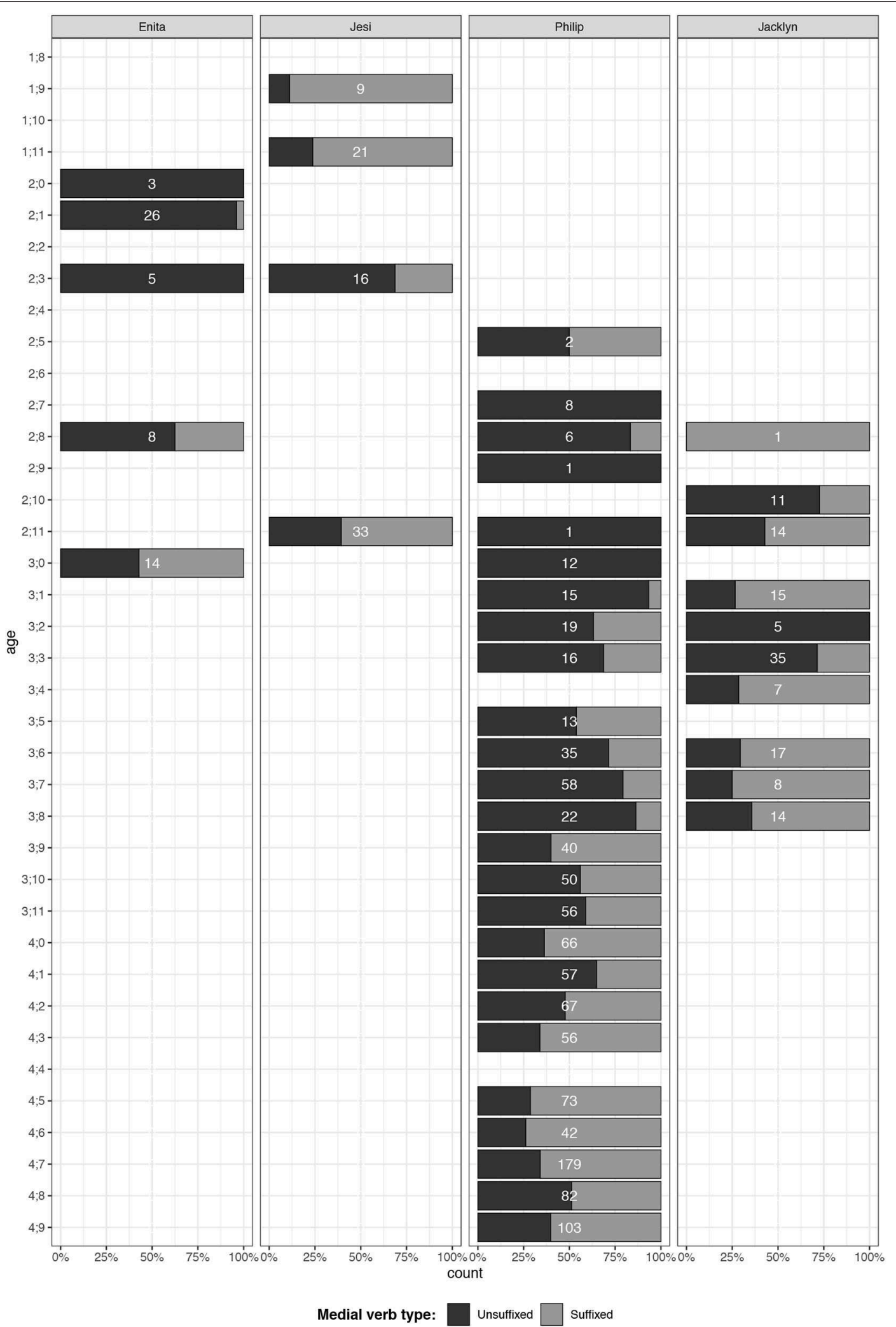

FIGURE 7 | Incidence of presence vs. absence of suffixes on Medial verbs used by the children. 


\section{ADULTS' AND OLDER CHILDREN'S SPEECH TO THE TARGET CHILDREN IN KU WARU}

As described in section Methodology and Description of the Data, we coded a sample of adult input to Philip and Jacklyn. It is important to note that this input is representative of only a small proportion of the speech that the children are exposed to. In particular, the recording situation was an unusual kind of context for both adult and child Ku Waru speakers, insofar as it involved more-or-less continuous, focused interaction centered on a single child, and a single adult caregiver (albeit with some additional input from older children and other adults in some of the sessions). Nonetheless, there do seem to be some clear overall patterns which are evident from the data, and contrast interestingly with the nature of child-directed speech that has been studied elsewhere.

In their child-directed speech, Ku Waru speakers do have distinct "baby talk" ways of simplifying some of the language's particularly difficult phonological features for children (Rumsey, 2017). There is a certain amount of baby talk lexicon that is used with very young ones, but not nearly as much as in some languages, such as the Australian Aboriginal language Warlpiri (Laughren, 1984). In addition, Rumsey and Merlan's observations over some 40 years of working with $\mathrm{Ku}$ Waru speakers are that adults do not slow down their speech nor use exaggerated intonation contours, as has been found in middleclass Western settings (Lieven, 1994). We will go on to show that Ku Waru adult caregivers do not simplify their clause chains or Medial verb morphology for children. In the next sections, we repeat each analysis in section The Emergence of Clause Chaining for the adults, in order to compare the children's production with their input.

\section{Chain Lengths in Adult Speech}

As addressed in section Two-Clause Chains, the children begin to produce unprompted two-clause chains between $1 ; 9$ and $2 ; 7$; three-clause chains at 2;8-3;3; and four-clause chains not until 4;7 (based on one child, Philip, for whom we have data extending into his fourth year). In terms of clause chain length, adults do not appear to "scale down" their speech to match the child's productive capacity (cf. Bohannon and Marquis, 1977 in Soderstrom, 2007; Sarvasy, 2019). Consider Figure 8, which shows clause chain length of adults' child-directed speech (in the top $42 \%$ of the range only, for greater resolution) (note that in Figure 8, as in Figure 1, that "Chain length: 1" in the legend denotes independent clauses). There may be some small increase in chain length production by adults that is associated with the children's increasing age. However, the overall impression is that $\mathrm{Ku}$ Waru children are not receiving a "baby talk" version of clause chains tailored to their own productive capacity. Philip's adult interlocutors (mainly his father) and Jacklyn's adult interlocutors (mainly her mother and uncle) maintain fairly steady proportions of chain lengths over the sample period. These even include four-, five-, and six-clause chains, despite the fact that Jacklyn never produces chains that long, and Philip only begins to produce four-clause chains at 3;10; five-clause ones at 4;7; and produces no six-clause chains at all.

It is interesting to note in Figure 8 the different linguistic styles of the adults in Philip's household vs. Jacklyn's. Multi-clause chains make up, on average, $25 \%$ of utterances to Philip, but only $13 \%$ to Jacklyn. But, as can be seen from Figure 1, this does not result in a higher overall incidence of multi-clause chains from Philip during the age range for which samples are available for both children $(2 ; 8-3 ; 8)$.

\section{The Kinds of Clause Chains Used by the Adults}

In section Patterns in the Kinds of Two-Clause Chains That Children Produce we presented an account of the kind of clause chains used by children, drawing in part on the data displayed in Figures 2-4. With reference to Figure 2, we pointed out that of the four Ku Waru inflections that occur in non-final position, only three of them were attested in the samples: Medial, Imminent, and SR1. The corresponding adult data are shown in Figure 9, showing the verb inflection in the next-to-last clause in any clause chain. Five things which stand out about the data there in relation to the data in Figure 2 are:

- As in the children's speech, Medial verbs are by far the most frequently occurring ones in non-final position.

- In non-final position, Medial verbs are followed in frequency by Imminent ones, in roughly the same proportions of Medialto-Imminent as in the children's speech after they turn 3.

- The adults maintain their proportions of Imminent verbs across the children's entire range of samples, including the earliest ones.

- Like the children, SR1 is very rare.

- SR2 is present in the speech of both Philip's interlocutors and Jacklyn's, albeit very infrequent in both cases; it is entirely absent in the children's production.

Turning now to the final-position counterparts of the Chameleon class inflections (Imminent, SR1, and SR2), with reference to Figure 3 in section Patterns in the Kinds of Two-Clause Chains That Children Produce, we pointed out that Optative verbs are fairly well-attested in the children's early recordings, but that the Subjunctive emerges much later and remains very infrequent right through to the end of Philip's range at $4 ; 9$. The corresponding adult data with regard to the Optative and the Subjunctive are shown in Figure 10. As in the children's speech, "other Final" class verbs are by far the most frequent. The proportion of Optatives in speech to Jacklyn remains quite constant throughout the range, in contrast to the widely fluctuating rate of Optatives from Jacklyn herself during that period. By contrast, the post-3;3 drop-off in their use by Philip that was noted in section Patterns in the Kinds of Two-Clause Chains That Children Produce is closely matched by a similar drop-off by his interlocutors after 3;5. The most surprising thing about the data in Figure 10 is that the Subjunctive does not occur at all in adult speech to Philip, whereas there are multiple instances of it from Philip himself; namely, six in his sample between 3;5 and 4;7. This must be related to the fact that Philip 


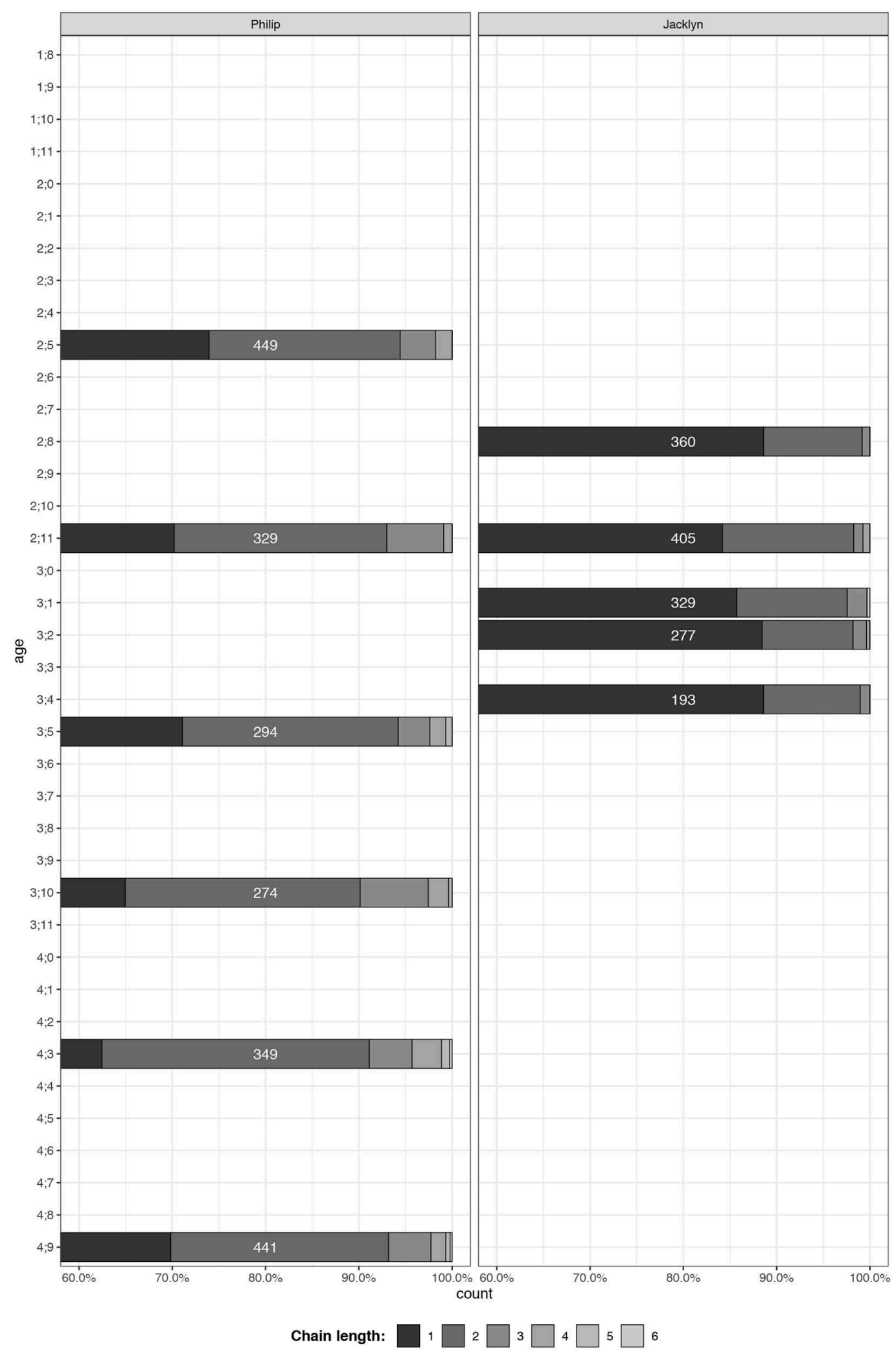

FIGURE 8 | Lengths of clause chains in speech of adults to Philip and Jacklyn. 


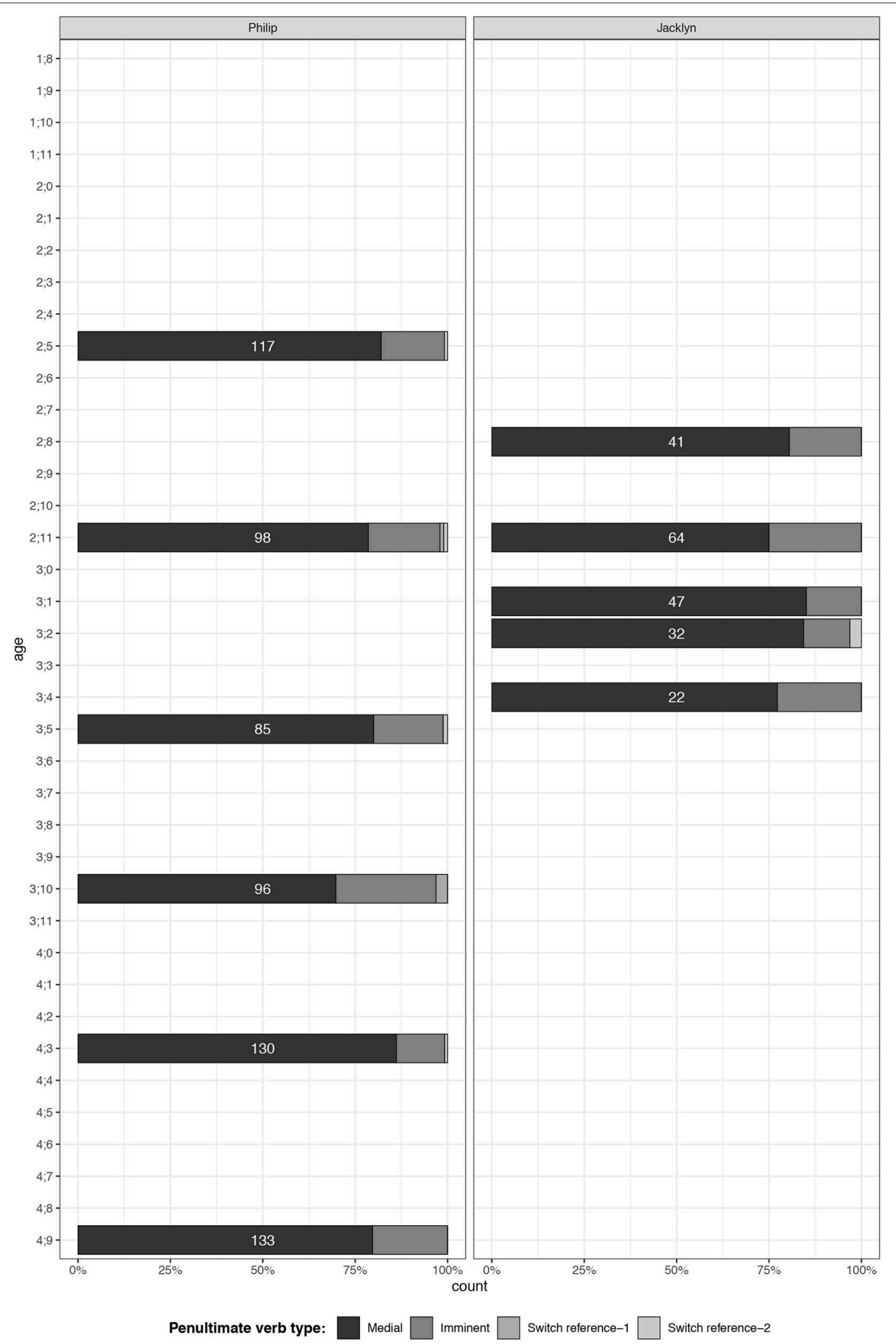

FIGURE 9 | Proportions of verb types in the second-to-last clauses in speech of adults to Philip and Jacklyn. 


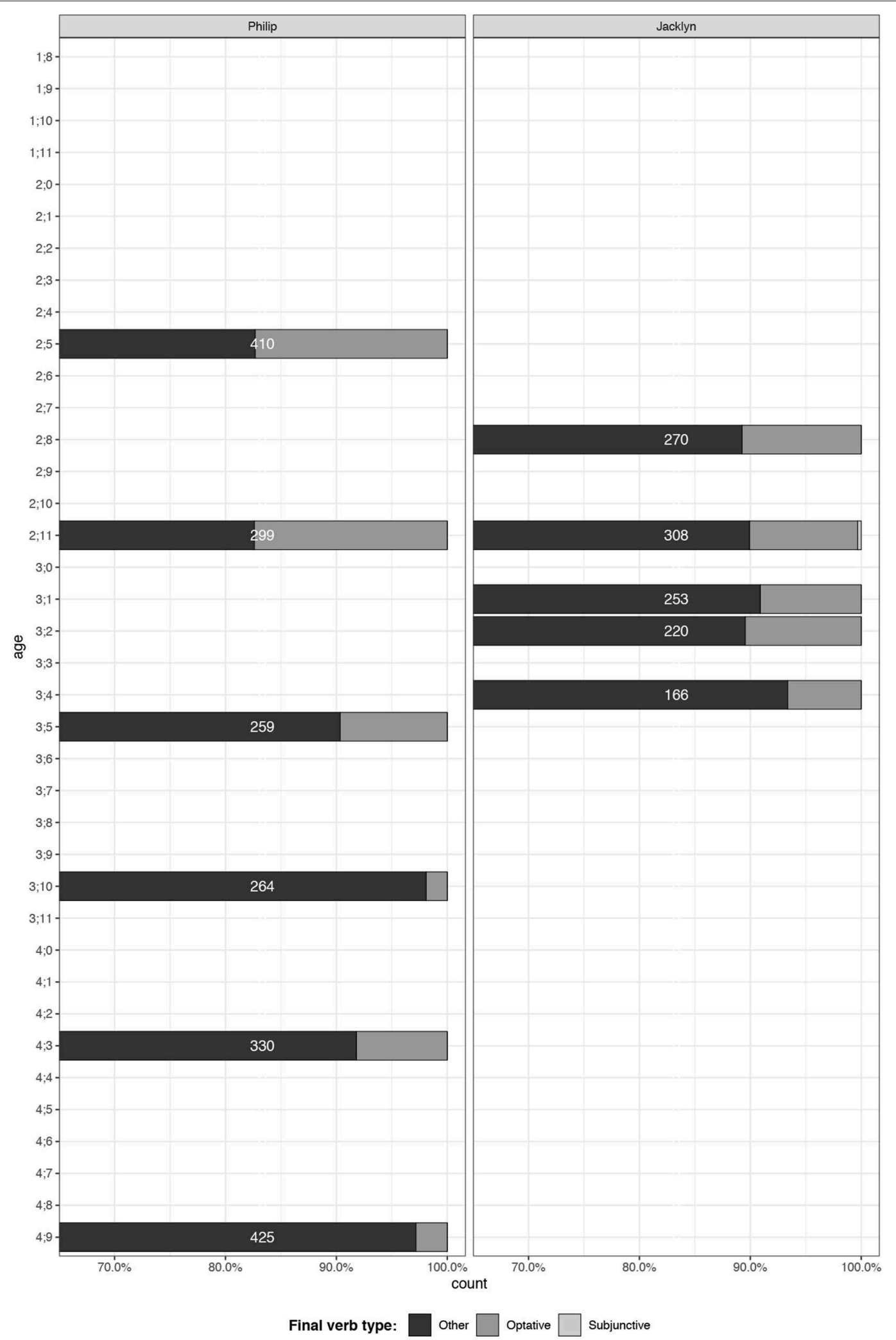

FIGURE 10 | Proportions of Optative and Subjunctive vs. other clause chain-final verbs in speech of adults to Philip and Jacklyn. 
in his everyday life experiences a wide range of other kinds of interaction besides the kind of dyadic conversational ones with his father that comprised most of the recording sessions on which the samples are based.

With reference to Figure 4 in section Patterns in the Kinds of Two-Clause Chains That Children Produce we discussed the incidence in the children's speech of the most common kinds of constructions, whether clause chains or independent clauses. The corresponding data for Philip's and Jacklyn's adult interlocutors are shown in Figure 11. The most notable point of comparison between Figures 4, 11 is that the most common kinds of twoclause chains and independent clauses are present from the start in the adult sample, and remain there in a consistent mix through the entire range, especially in the case of Philip's interlocutors. This contrasts with the children's production of these most common constructions, which show a mix that gradually increases in complexity.

\section{Clause Chains and Event Structure in Adult Speech}

In section Clause Chains and Event Structure in the Children's Speech in Figure 5, we presented data concerning the ratio of clauses to events in the children's two-clause chains, showing that this ratio does not change markedly for any of the four children over time. Figure 12 shows the corresponding data for Philip's and Jacklyn's adult interlocutors. As can be seen there, the same pattern holds true for them, with roughly the same overall proportion of clauses to events.

In Figure 6 in section Clause Chains and Event Structure in the Children's Speech, we showed the mean number of clauses in the three- to five-clause chains in each sample from Philip across the age range when he produces them $(3 ; 2-4 ; 8)$. We established that the ratio of chain length to number of events does not change markedly over that time. Figure $\mathbf{1 3}$ shows that the same pattern holds true for Philip's adult interlocutors; that is, ratio of chain length to number of events does not change markedly over time.

\section{Presence or Absence of Medial Marking in the Adults' Speech}

As discussed in section The Presence vs. Absence of Medial Verb Marking, and displayed in Figure 7, when the children first begin to produce Medial verbs, they vary as to whether these verbs are suffixed or unsuffixed. To recap, Jacklyn and Jesi are fairly consistent in their proportions of suffixed vs. unsuffixed Medial verbs, whereas Enita and Philip show a slow progression from unsuffixed verbs to suffixed ones. In terms of adult input, Figure 14 shows that adults are not adopting the children's greater tendency to produce unsuffixed Medial verbs. Philip receives very consistent input in terms of Medial morphology, with an average of $95 \%$ of Medial verbs with suffixes. The first session for Jacklyn has a lower proportion of unsuffixed Medial verbs-65\%-but the adults interacting with her become fairly consistent in the later sessions, averaging $81 \%$ of verbs with suffixes. Again, it is interesting to note the difference between Philip and Jacklyn's linguistic environments, with Philip's carers being more canonical in terms of full morphological marking on
Medial verbs. But just as we have seen in section Chain Lengths in Adult Speech regarding adults' clause chaining, this is not matched by a higher rate of suffixation by Philip than by Jacklyn. That is, while Jacklyn is exposed to a much lower incidence of clause chains (vs. single verb clauses) than Philip in these samples, she produces them at roughly the same rate as Philip across her sample period. Correspondingly, although Jacklyn is addressed with lower rates of Medial suffixation, she does not produce it at lower rates than Philip. On the contrary, she produces it at higher rates across most of the age range for which there are samples from both children $(2 ; 8-3 ; 8)$.

To conclude this section, there is an overall correspondence between the children's and the adults' clause chain production in terms of the relative frequency of shorter vs. longer chains (Figure 8), and of certain kinds of chains as compared with others (Figures 9, 10). However, there are big differences between the relative consistency of the adults' speech over time, and the changes in the children's speech as it 'catches up' with that of the adults. That is, the adults address the children when they are toddlers in much the same way as they do at the later ages in our samples, when the children's clause chaining becomes more like that of the adults. In order to better understand the children's progress in these respects from $2 ; 5$ to $4 ; 9$, it would be important to include a far larger sample of children's interaction with other children than is present in the corpus for this study ${ }^{18}$. What we can say with confidence based on the data examined in sections Clause Chains and Event Structure in the Children's Speech and Clause Chains and Event Structure in Adult Speech is that throughout the course of the children's acquisition of clause chaining, there is a sizeable proportion of clause combinations that refer to single events; that this proportion remains fairly constant over that period; and that it closely matches that of the adult interlocutors at all stages.

\section{CONCLUSIONS}

In this article we have traced the development of clause chains in the speech of four Ku Waru-speaking children between the ages of $1 ; 8$ and $4 ; 9$. Our data have been drawn from a longitudinal corpus of 40 sessions of recorded and transcribed interaction between the children and their adult caregivers, which comprise a total of 32,760 reviewed lines. The speech of the children in all of those sessions has been coded for relevant verb types, and analyses drawn from this coding. In order to study possible effects of the caregivers' speech on the children's learning of clause chaining, we have applied the same coding protocols to adult input in a temporally spaced subset of the sessions involving two of the children.

As shown by the discussion in section The Emergence of Clause Chaining, there are differences among the children in the ages at which they acquire the various aspects of clause chaining discussed there. However, all the children follow the same series of steps in doing so, with regard to: (i) the length

\footnotetext{
${ }^{18}$ We hope to be able to do so in the future, based on $\sim 30 \mathrm{~h}$ of interaction that we have recorded, using chest-mounted GoPro video cameras, of children interacting with each other without any adults on the scene.
} 


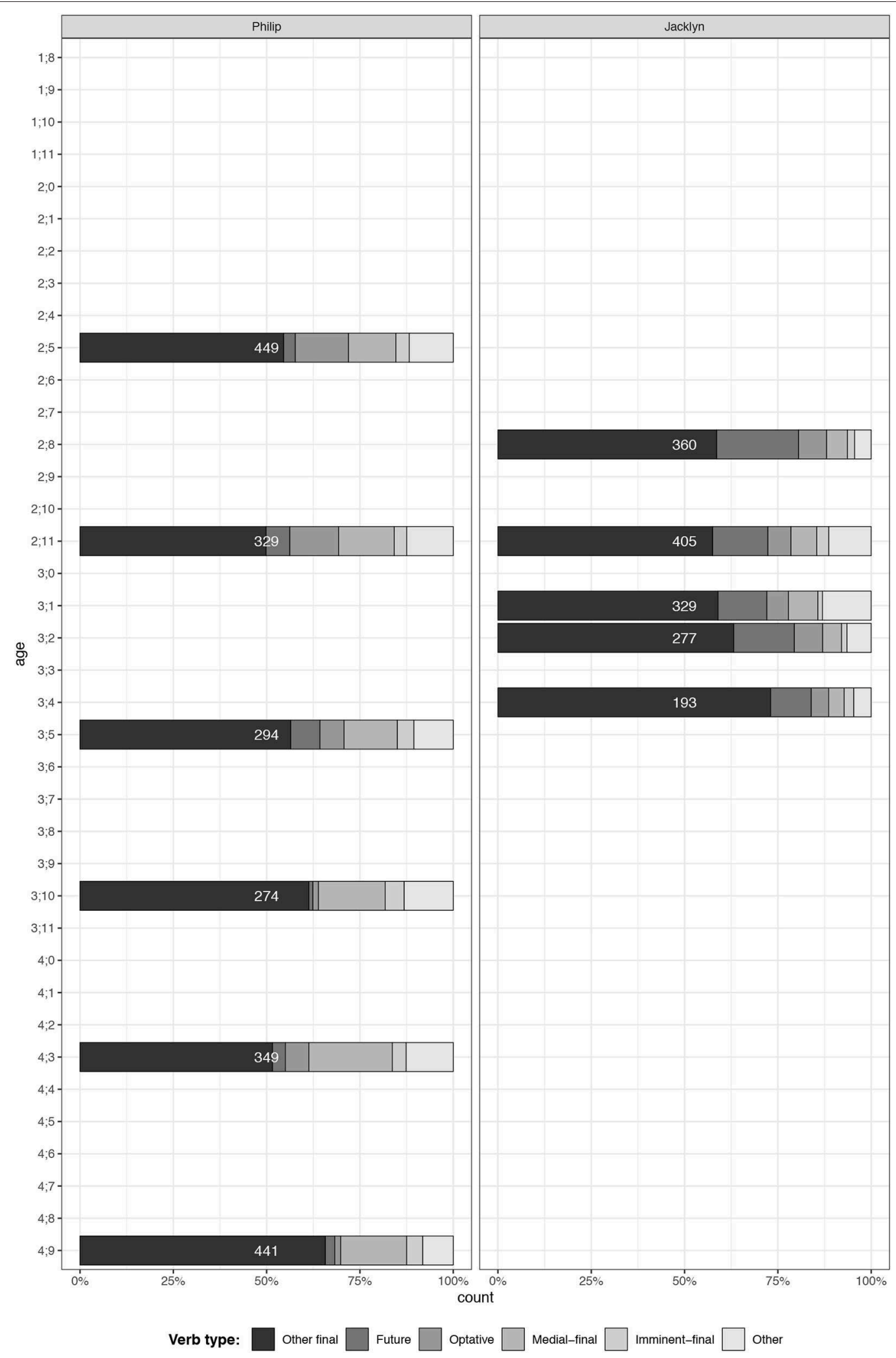

FIGURE 11 | Incidence of common construction types in adults' speech to Philip and Jacklyn. 


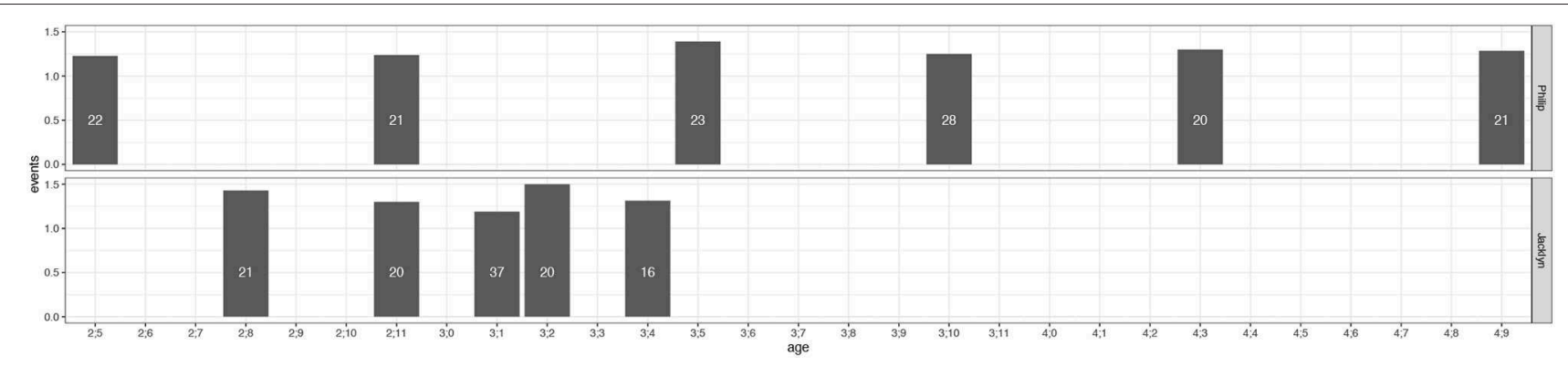

FIGURE 12 | Mean number of events referred to in the adults' two-clause chains.

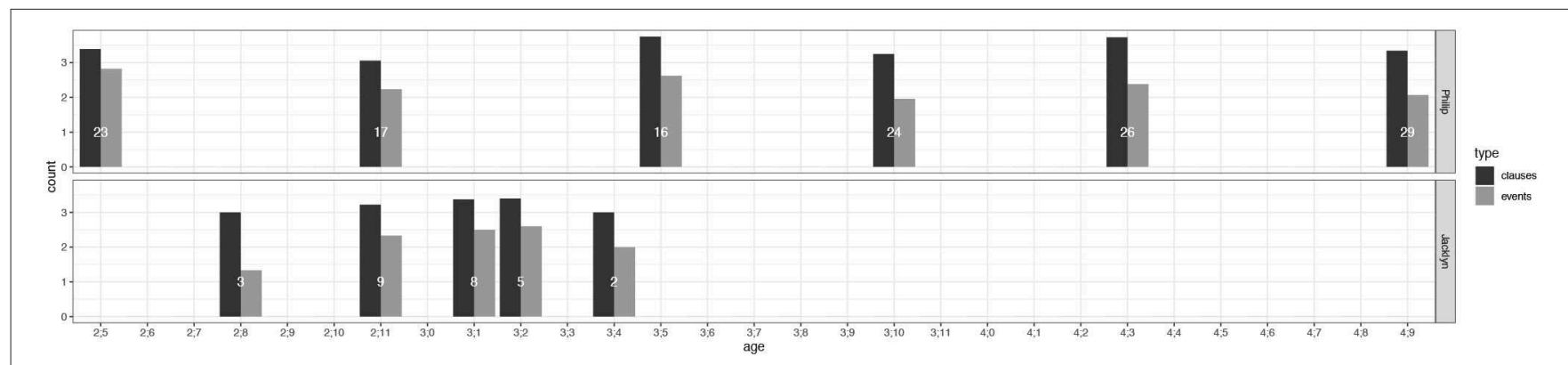

FIGURE 13 | Clauses vs. events in the adults' clause chains of three clauses or more.

of the chains (Figure 1), (ii) the verbal inflections that feature in chains (Figures 2, 3), and (iii) the proportions of common types of clause chains and independent clauses that they produce (Figure 4). Although the samples for some of the children in our study are not as numerous or frequent as in many longitudinal studies, we think that having four children does lend added credibility to our findings regarding that uniform sequence of developmental stages.

As discussed in section Adults' and Older Children's Speech to the Target Children in Ku Waru, the adults provide rich input that generally runs well-ahead of what the children are producing at the time of the sample. There is little or no apparent attempt on the part of the adults to scale down their speech in order to accommodate the children's current stage of development. Our findings in that respect are consistent with those of Schieffelin in her (1990) monograph on the language socialization of children among the Kaluli people in the Bosavi region to the southwest of Ku Waru. Schieffelin reports that there is no distinct "baby talk" register among the Kaluli. Indeed, the Kaluli believe that the right way to teach children to talk is by addressing them with "hard language" that will model fully competent adult speech for them (Feld and Schieffelin, 1982). In the speech to Ku Waru children, $\mathrm{Ku}$ Waru caregivers use adult-like morphosyntactic features that are perhaps the functional equivalent of Kaluli "hard language."

There are three other aspects of our findings that we think raise especially interesting questions for comparative study. One is the acquisition of switch-reference marking. It seems remarkable that none of our four target children began using this before $4 ; 7$. But that becomes far less remarkable in light of our findings concerning the scarcity of switch-reference marking in all of the adult speech in our samples. Indeed, this is consistent with low rates of usage in $\mathrm{Ku}$ Waru adult-to-adult speech that Merlan and Rumsey have experienced over the years, and noted in our extensive adult $\mathrm{Ku}$ Waru text corpus. Given that very limited adult input, it is not clear whether the special cognitive demands of switch-reference marking that we noted in section Patterns in the Kinds of Two-Clause Chains that Children Produce necessarily preclude children's mastering it at earlier ages than 4;7. That is an open empirical question which could be better studied in a setting where switch-reference marking is far more common than among Ku Waru speakers.

A second especially interesting comparative issue raised by our study concerns the nature and functions of clause chaining itself. As noted in section Introduction, it is often assumed that the prototypical function of clause chaining is reference to multiple events in sequence. However, as shown by our data in sections The Emergence of Clause Chaining and Adults' and Older Children's Speech to the Target Children in $\mathrm{Ku}$ Waru, clause chaining serves many other functions in $\mathrm{Ku}$ Waru, including durative aspect marking, adverbial qualification, expression of intentionality, and the lexicalized expression of basic concepts such as "bring," "take," "tell," and "think" through the regular combination of particular verbs in particular orders. That being the case, as shown by the extensive data summarized in sections Clause Chains and Event Structure in the Children's Speech and Clause Chains and Event Structure in Adult Speech, and exemplified in sections Patterns in the Kinds of Two-Clause Chains that Children Produce and Kinds of Clause Chains Used 


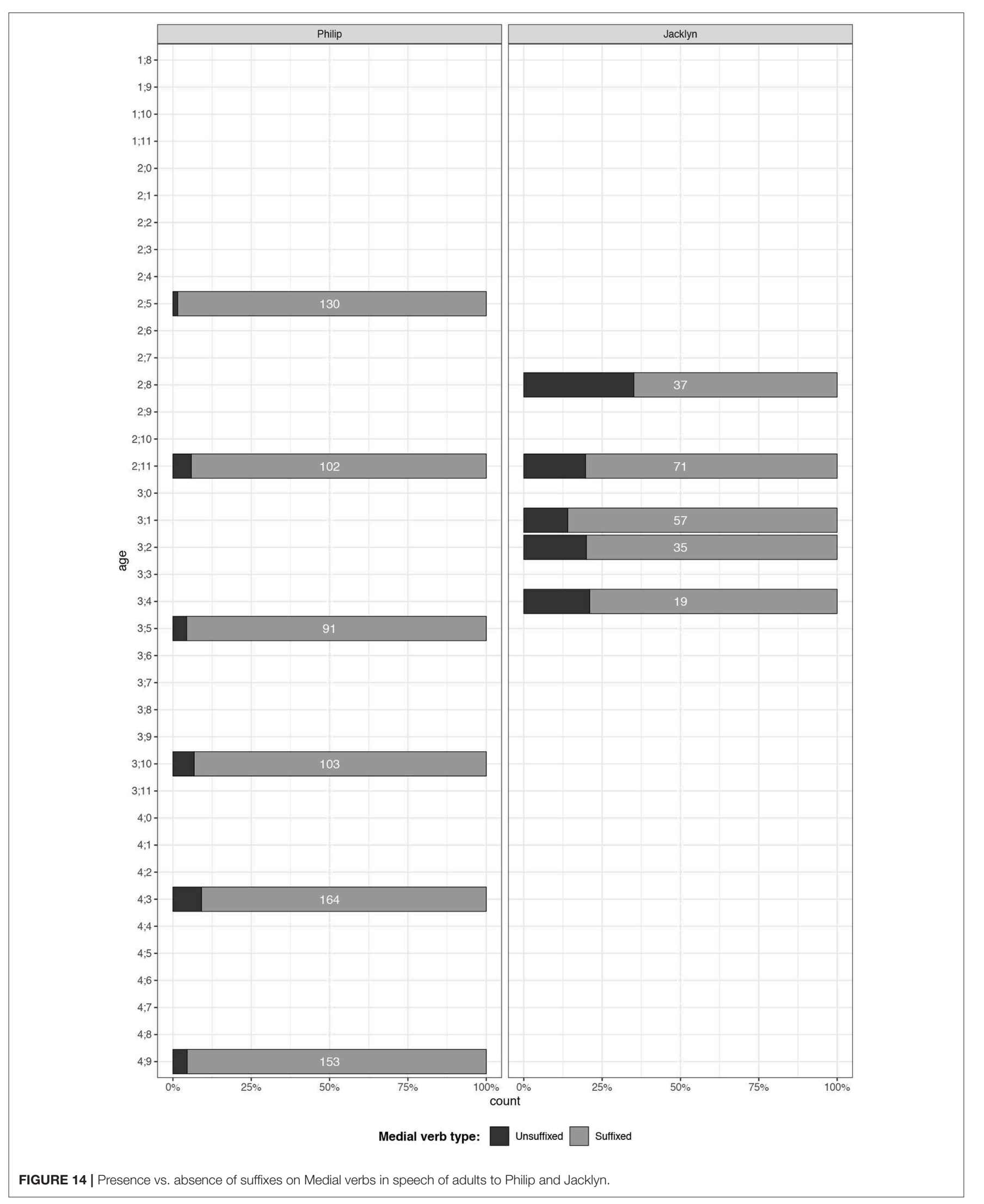


by the Adults, most occurring clause chains in $\mathrm{Ku}$ Waru refer to fewer events than the number of verbs in them. It is mainly in narrative contexts such as in (15), (50), and (52) that speakers construct long clause chains referring to multiple events in sequence. It is not surprising that $\mathrm{Ku}$ Waru children do not begin to construct long, multi-event clause chains like this until they are 4-5 years old, given the cross-linguistic finding that children's narrative skills begin to develop strongly only at around that age (Clark, 2009, p. 331-335).

Hence, this study raises the question of the extent to which the principal function of clause chaining in the world's languages is to refer to multiple events in sequence-a question that pertains to adults' speech as much as to children's. Other subsidiary questions are the following:

- To what extent are clause chains in other languages used for grammatical or lexical functions, such as the Ku Waru aspectual and adverbial functions of certain lexicalized and grammaticalized chains?

- At what age do children begin to regularly produce long clause chains, and what do they use them for?

- To what extent are long clause chains limited to narrative contexts, or other registers (both for children and adults)?

We hope this article will have helped to establish a useful framework for investigating those questions in other languages where clause chaining is found.

The third comparative issue is the main one in terms of which this article is framed: the comparison of our findings with those of Diessel (2004) for English. Before turning to that issue we will attempt to account for some of the differences between the two cohorts in our study: Enita and Jesi during 2004-2006 and Philip and Jacklyn during 2013-2016. As noted in section Two-Clause Chains, Enita and Jesi produce two-clause chains much earlier than Philip and Jacklyn. As discussed in section Patterns in the Kinds of Two-Clause Chains That Children Produce, Jesi uses the Imminent inflection at $1 ; 11$, whereas Philip does not do so until 3;1. A difference between the two time periods that may have played a role in this developmental difference is that by 2013, most children in the study area at Kailge were learning Tok Pisin in addition to $\mathrm{Ku}$ Waru from the start of their language learning ${ }^{19}$. By contrast, in 2004-2006 children were not learning Tok Pisin until later on, at the age of four or five. Based on the same transcript data used in this article for Philip at 2;4-2;6 and Jacklyn at 2;11-3;1, Merlan and Rumsey (2015) show that some Tok Pisin is used by both children and their parents in all six of the sessions, in $\sim 6 \%$ of the conversational turns in the sessions with Philip, and in rates of $16-32 \%$ across the three sessions with Jacklyn. By contrast, in the 2004-2006 sessions with Jesi and Enita, there is almost no Tok Pisin used. Studies of bilingual language learning elsewhere (Hoff et al., 2012) have shown it to be correlated with initially delayed language development in

\footnotetext{
${ }^{19}$ This was due at least in part to a conscious decision that had been made by some parents to address their children partly in Tok Pisin from the onset of their language learning, on the assumption that it would give the children a head start toward learning English when they went to school. For details see Merlan and Rumsey (2015).
}

both languages, relative to that of monolingual language learners. Accordingly, the later acquisition of clause chaining by Jacklyn and Philip may be due in part to their bilingual language learning. But this is unlikely to have been a major factor, given that Jacklyn's Ku Waru development is on par with that of Philip, notwithstanding the fact that she uses Tok Pisin at approximately four times the rate that he does.

Returning now to the comparison of our results with Diessel's regarding English-speaking children's acquisition of complex sentences, there are both similarities and differences between our findings and his, which may be related to the differences between the kinds of constructions being acquired. Recall that one of Diessel's conclusions for subordinate constructions in English was that children's early ones "are organized around concrete lexical expressions, and although they consist of two clauses, they only contain a single proposition" (Diessel, 2004, p. 174175). The same is true of Ku Waru children's acquisition of clause chaining, as shown by the discussion of the children's first two-clause chains in sections Two-Clause Chains and Patterns in the Kinds of Two-Clause Chains That Children Produce. As discussed in section Patterns in the Kinds of Two-Clause Chains That Children Produce, the majority of them are lexicalized or grammaticalized combinations (e.g., with a "stay" verb in final position used to mean "keep doing"). In line with Diessel's findings, most of the Ku Waru children's first two-clause chains do not refer to two different events or states of affairs, but to single ones.

However, contrary to Diessel's finding regarding English subordinate constructions, $\mathrm{Ku}$ Waru children do not develop their mastery of clause chaining as a process of "clause expansion," whereby single-event multi-clause constructions expand from within to become complex sentences. Rather, they do it through a process of what can be called clause chain expansion. This works as follows. Firstly, children acquire the clause-chain formal framework via lexicalized or grammaticalized clause chains; that is, they acquire Medial and non-final Chameleon class marking by learning it through comprehension and production of clause chains which refer to single events. This framework can then be applied to produce novel constructions which refer to multiple events and are more diverse with regard to the lexical verbs that occur in them. As shown by the data in section Clause Chains and Event Structure in the Children's Speech, this involves an increase in the number of distinct events that the children are capable of linking up into a sequence within a single clause chain (here we are not referring to the ratio of clauses to events, but rather to the number of events alone). In that respect, the acquisition process is like the one for English coordinate constructions, which Diessel describes as one of "integration."

With respect to all of the processes referred to above, the $\mathrm{Ku}$ Waru children's developmental trajectories conform closely to what they are exposed to in the speech of adults and older children, as shown in section Adults' and Older Children's Speech to the Target Children in $\mathrm{Ku}$ Waru. Of particular relevance here is our finding that, within clause chains, the unexpectedly low ratio of events to clauses that is evident in the children's speech is closely matched in that of the adults. Moreover, it 
remains relatively constant, both across the children's age ranges and within the speech of adults to the children across those ranges. This contrasts with Diessel's findings for the acquisition of English subordinate constructions. Diessel shows the acquisition of those constructions to be in part a process of moving from largely single-event constructions to one-event-per-clause constructions. By contrast, at least after the initial two-clause period described in section Patterns in the Kinds of TwoClause Chains That Children Produce, Ku Waru children do not increase their ratio of events-to-clauses over time.

We hypothesize that this developmental difference may be conditioned in part by the structural and functional differences between subordinate constructions and coordinate-dependent ones. That is, as a variety of the latter, clause chains involve reference to multiple events as one of their functions, as do the coordinate-non-dependent constructions studied by Diessel. But clause chains also involve particular combinations of clauses that refer to single events. In that respect they are unlike either subordinate constructions or coordinate-non-dependent ones, and this is reflected in the developmental pathways by which children learn them. Investigation of that hypothesis would require further research on the acquisition of clause chaining in other languages, along the lines that we have pursued here with respect to $\mathrm{Ku}$ Waru.

\section{DATA AVAILABILITY STATEMENT}

The datasets for this article are not yet publicly available because they are in the process of being archived with PARADISEC (the Pacific and Regional Archive for Digital Sources in Endangered Cultures). This will be completed over 2020. Requests to access the datasets should be directed to Alan Rumsey, alan.rumsey@anu.edu.au.

\section{ETHICS STATEMENT}

The studies involving human participants were reviewed and approved by Australian National University Human Research Ethics Committee, protocol 2013/055. Written informed consent

\section{REFERENCES}

Aikhenvald, A. (2018). Serial Verbs. Oxford: Oxford University Press. doi: 10.1093/oso/9780198791263.001.0001

Bohannon, J. N., and Marquis, A. L. (1977). Children's control of adult speech. Child Dev. 48, 1002-1008. doi: 10.1111/j.1467-8624.1977.tb01259.x

Brandt, S., Diessel, H., and Tomasello, M. (2008). The acquisition of German relative clauses: a case study. J. Child Lang. 35, 325-348. doi: 10.1017/S0305000907008379

Brandt, S., Kidd, E., Lieven, E., and Tomasello, M. (2009). The discourse bases of relativization: An investigation of young German and English-speaking children's comprehension of relative clauses. Cogn. Linguist. 20, 539-570. doi: 10.1515/COGL.2009.024

Clark, E. V. (2009). First Language Acquisition. Cambridge; New York, NY: Cambridge University Press. doi: 10.1017/CBO9780511806698

Diessel, H. (2004). The Acquisition of Complex Sentences. Cambridge; New York, NY: Cambridge University Press. doi: 10.1017/CBO9780511486531

Diessel, H., and Tomasello, M. (2005). A new look at the acquisition of relative clauses. Language 81, 882-906. doi: 10.1353/lan.2005.0169 to participate in this study was provided by the participants' legal guardian/next of kin.

\section{AUTHOR CONTRIBUTIONS}

AR and FM facilitated participant and research assistant recruitment, recording and transcription of the data for this study, and located and glossed the Ku Waru examples in the text. AR and LR conceived of coding protocols for verbs, and statistical analyses and worked with a research assistant to run these and produce associated graphs. AR, LR, and FM coded the data for verbs and wrote the manuscript. FM conceived of coding protocols with respect to prompting and event structure, and coded the data for those. All authors contributed to manuscript revision, and read and approved the submitted version.

\section{FUNDING}

For funding the research on which this article was based, we are very grateful to the Australian Research Council, the Centre of Excellence for the Dynamics of Language (Grant Nos. DP130101655 and CE140100041), and the Australian National University.

\section{ACKNOWLEDGMENTS}

We acknowledge and thank the Ku Waru families who participated in this study, and field assistants John Onga and Andrew Noma for their work on facilitation, recording and transcription. We acknowledge the work of project corpus managers Tom Honeyman and Charlotte Van Tongeren, who both worked extensively cleaning the transcripts. Tom Honeyman also worked with Appen to refine typing of the transcripts. We thank Siva Kalyan for his expertise in $\mathrm{R}$ in helping us visualize our data. For pointing us to literature on the acquisition of complex sentences, we thank Evan Kidd. For further references, and for their helpful comments on earlier versions of the manuscript, we thank Soonja Choi, Hannah Sarvasy, Bambi B. Schieffelin.

Dooley, R. A. (2010). "Exploring clause chaining" in SIL Electronic Working Papers. Available online at: https://www.sil.org/resources/publications/entry/ 7858 (accessed November 1, 2019).

Eberhard, D. M., Simons, G. F., and Fennig, C. D. (2019). Ethnologue: Languages of the World. 22nd Edn. Dallas, TX: SIL International. Available at: http://www. ethnologue.com (accessed November 15, 2019).

Feld, S., and Schieffelin, B. B. (1982). "Hard talk: a functional basis for Kaluli discourse," in Analyzing Discourse: Text and Talk, ed D. Tannen (Washington, DC: Georgetown University Press), 229-243.

Foley, W. (1986). Papuan Languages of New Guinea. Cambridge: Cambridge University Press.

Foley, W., and Olson, M. (1985). "Clausehood and verb serialisation," in Grammar Inside and Outside the Clause: Some Approaches to Theory from the Field, eds J. Nichols and A. C. Woodbury (Cambridge: Cambridge University Press), 17-60.

Foley, W. A. (2010). "Clause linkage and nexus in Papuan languages," in Clause Linkage and Clause Hierarchy: Syntax and Pragmatics, ed I. Bril (Amsterdam: John Benjamins B.V.), 27-50. doi: 10.1075/slcs.121. 02 fol 
Grinstead, J., Lintz, P., Vega-Mendoza, M., De la Mora, J., Cantú-Sánchez, M., and Flores-Avalos, B. (2014). Evidence of optional infinitive verbs in the spontaneous speech of Spanish-speaking children with SLI. Lingua 140, 52-66. doi: 10.1016/j.lingua.2013.11.004

Haspelmath, M. (1995). "The converb as a cross-linguistically valid category," in Converbs in Cross-linguistic Perspective, eds M. Haspelmath and E. König (Berlin: Mouton de Gruyter), 1-55.

Hoekstra, T., and Hyams, N. (1998). Aspects of root infinitives. Lingua 106, 81-112. doi: 10.1016/S0024-3841(98)00030-8

Hoff, E., Core, C., Place, S., and Rumiche, R. (2012). Dual language exposure and early bilingual development. J. Child Lang. 39, 1-27. doi: $10.1017 /$ S0305000910000759

Kidd, E., Brandt, S., Lieven, E., and Tomasello, M. (2007). Object relatives made easy: a cross-linguistic comparison of the constraints influencing young children's processing of relative clauses. Lang. Cogn. Proc. 6, 860-897. doi: 10.1080/01690960601155284

Kidd, E., Lieven, E., and Tomasello, M. (2006). Examining the role of lexical frequency in children's acquisition of sentential complements. Cogn. Dev. 21, 93-107. doi: 10.1016/j.cogdev.2006.01.006

Knowles, J. E. (2019). eeptools: Convenience Functions for Education Data. R Package Version 1.2.2. Available online at: https://CRAN.R-project.org/ package $=$ eeptools (accessed March 26, 2020).

Köymen, B., Lieven, E., and Brandt, S. (2016). Syntactic and semantic coordination in finite complement-clause constructions: a diary-based case study. J. Child Lang. 43, 22-42. doi: 10.1017/S0305000914000853

Laughren, M. (1984). Warlpiri baby talk. Aust. J. Linguist. 4, 73-88. doi: 10.1080/07268608408599321

Lieven, E. (1994). "Crosslinguistic and crosscultural aspects of language addressed to children," in Input and Interaction in Language Acquisition, eds C. Gallaway and B. Richards (Cambridge: Cambridge University Press), 56-73. doi: 10.1017/CBO9780511620690.005

Longacre, R. E. (2007). "Sentences as combinations of clauses," in Language Typology and Syntactic Description: Complex Constructions, 2nd Edn, ed T. Shopen (Cambridge: Cambridge University Press), 372-420. doi: 10.1017/CBO9780511619434.007

Merlan, F., and Rumsey, A. (1991). Ku Waru: Language and Segmentary Politics in the Western Nebilyer Valley. Cambridge: Cambridge University Press. doi: 10.1017/CBO9780511518218

Merlan, F., and Rumsey, A. (2015). Language ecology, language policy and pedagogical practice in a Papua New Guinea Highland community. Lang. Linguist. Melanesia 33, 82-96.

Merlan, F., and Rumsey, A. (2017). "Flexibles and polyvalence in Ku Waru: a developmental perspective," in Lexical Polycategoriality: Cross-linguistic, Crosstheoretical and Language Acquisition Approaches, eds V. Vapnarsky and E. Veneziano (Amsterdam: John Benjamins Publishing Company), 307-341. doi: $10.1075 /$ slcs.182.11mer

Pawley, A., and Hammerström, H. (2017). "The Trans New Guinea family," in The Languages and Linguistics of the New Guinea Area: A Comprehensive Guide, ed B. Palmer (Berlin; Boston, MA: De Gruyter), 21-196. doi: 10.1515/9783110295252-002

R Core Team (2018). R: A Language and Environment for Statistical Computing. Vienna: R Foundation for Statistical Computing. Available at: https://www.Rproject.org/(accessed March 26, 2020).

Rizzi, L. (1994). Some notes on linguistic theory and language development: the case of root infinitives. Lang. Acquis. 3, 371-393. doi: 10.1207/s15327817la0304_2
Roberts, J. R. (1988). Amele switch-reference and the theory of grammar. Linguist. Inq. 19, 45-63.

Rumsey, A. (2017). “Dependency and relative determination in children's language acquisition: The case of Ku Waru," in Dependencies in Language: On the Causal Ontology of Linguistic Systems, ed N. J. Enfield (Berlin: Language Science Press), 97-114.

Rumsey, A. (2019). "Melanesia as a zone of linguistic diversity," in The Melanesian World, eds E. Hirsch and W. Rollason (London: Routledge), 110-125. doi: 10.4324/9781315529691-6

Rumsey, A., San Roque, L., and Schieffelin, B. B. (2013). "The acquisition of ergative marking in Kaluli, Ku Waru and Duna (Trans New Guinea)," in The Acquisition of Ergativity, eds E. L. Bavin and S. Stoll (Amsterdam: John Benjamins Publishing Company), 133-182. doi: 10.1075/tilar.9.06rum

Sarvasy, H. (2015). Breaking the clause chains: non-canonical medial clauses in Nungon. Stud. Lang. 39, 664-696. doi: 10.1075/sl.39.3. 05sar

Sarvasy, H. (2019). The root nominal stage: a case study of early Nungon verbs. J. Child Lang. 46, 1073-1101. doi: 10.1017/S030500091900 0357

Schauberger, P., and Walker, A. (2019). openxlsx: Read, Write and Edit xlsx Files. R Package Version 4.1.3. Available online at: https://CRAN.R-project.org/ package $=$ openxlsx (accessed March 26, 2020).

Schieffelin, B. B. (1990). The Give and Take of Everyday Life: Language Socialization of Kaluli Children. Cambridge: Cambridge University Press.

Soderstrom, M. (2007). Beyond babytalk: re-evaluating the nature and content of speech input to preverbal infants. Dev. Rev. 27, 501-532. doi: 10.1016/j.dr.2007.06.002

Thurman, R. C. (1975). Chuave medial verbs. Anthropol Linguist. 17, 342-352.

Van Valin, R. D., and LaPolla, R. J. (1997). Syntax: Structure, Meaning, and Function. Cambridge: Cambridge University Press. doi: 10.1017/CBO9781139166799

Weisser, P. (2015). Derived Coordination: A Minimalist Perspective on Clause Chains, Converbs and Asymmetric Coordination. Berlin: Walter de Gruyter. doi: $10.1515 / 9783110443578$

Wexler, K. (2011). "Grammatical computation in the optional infinitive stage," in Handbook of Generative Approaches to Language Acquisition, eds J. de Villiers and T. Roeper (New York, NY: Springer Science+Business Media), 53-118. doi: 10.1007/978-94-007-1688-9 3

Wickham, H., Averick, M., Bryan, J., Chang, W., D’Agostino McGowan, L., François, R., et al. (2019). Welcome to the tidyverse. J. Open Source Soft. 4:1686. doi: 10.21105 /joss.01686

Wickham, H., and Bryan, J. (2019). readxl: Read Excel Files. R Package Version 1.3.1. Available online at: https://CRAN.R-project.org/package=readxl (accessed March 26, 2020).

Conflict of Interest: The authors declare that the research was conducted in the absence of any commercial or financial relationships that could be construed as a potential conflict of interest.

Copyright (c) 2020 Rumsey, Reed and Merlan. This is an open-access article distributed under the terms of the Creative Commons Attribution License (CC BY). The use, distribution or reproduction in other forums is permitted, provided the original author(s) and the copyright owner(s) are credited and that the original publication in this journal is cited, in accordance with accepted academic practice. No use, distribution or reproduction is permitted which does not comply with these terms. 